\title{
Large-scale inflatable structures for tunnel protection: a review of the Resilient Tunnel Plug project
}

\author{
Eduardo M. Sosa ${ }^{*}$, Gregory J. Thompson', Gregory M. Holter ${ }^{2}$ and John M. Fortune ${ }^{3}$
}

\begin{abstract}
The protection of underground civil infrastructure continues to be a high priority for transportation and transit security agencies. In particular, rail transit tunnels running under bodies of water are susceptible to disruptions due to flooding caused by extraordinary climatic events such as hurricanes or other events resulting from human activities. Several events have taken place in the past decades that have demonstrated the need to mitigate vulnerabilities or, at least, minimize the consequences of catastrophic events. Although it is impossible to prevent all situations that can lead to flooding, damage can be substantially decreased by reducing the area affected by the event. To minimize the effects of an event, a possible approach is to compartmentalize the tunnel system by creating temporary barriers that can contain the propagation of flooding until a more permanent solution can be implemented. One way to create a temporary barrier is by the deployment of a large-scale inflatable structure, also known as an inflatable plug. In such an application, the inflatable structure is prepared for placement, either permanently or temporally, and maintained ready for deployment, inflation, and pressurization when needed. The internal plug pressure imparts a normal force against the tunnel wall surface with the friction between the plug and tunnel surfaces opposing axial movement of the plug. The sealing effectiveness depends on the ability of the inflatable structure to self-deploy and fit, without human intervention, to the intricacies of the perimeter of the conduit being sealed. Primary design constraints include having the plug stowed away from the dynamic envelope of the trains and being able to withhold the pressure of the flooding water. This work presents a compilation of the main aspects of the activities completed for the development of large-scale inflatable structures as part of the Resilient Tunnel Plug (RTP) Project. The main test results and lessons learned are presented to demonstrate the viability of implementing large-scale inflatable plugs for the containment of flooding in rail tunnels systems. Over 400 coupon and specimen tests, 200 reduced scale tests, and 100 full-scale tests were conducted to demonstrate the efficacy of the design of different prototypes over a 10-year research and development project. The culmination of the work was 12 large-scale flooding demonstrations where the inflatable tunnel plug was shown able to be deployed remotely and withstand a simulated flooding event.
\end{abstract}

Keywords: Confined inflatable, Conformity, Deployment, Inflation, Folding, Membrane, Plug, Tunnel, Vectran

\footnotetext{
* Correspondence: eduardo.sosa@mail.wvu.edu

'Department of Mechanical and Aerospace Engineering, West Virginia

University, Morgantown, W, USA

Full list of author information is available at the end of the article
}

\section{Springer Open}

(c) The Author(s). 2020 Open Access This article is licensed under a Creative Commons Attribution 4.0 International License, which permits use, sharing, adaptation, distribution and reproduction in any medium or format, as long as you give appropriate credit to the original author(s) and the source, provide a link to the Creative Commons licence, and indicate if changes were made. The images or other third party material in this article are included in the article's Creative Commons licence, unless indicated otherwise in a credit line to the material. If material is not included in the article's Creative Commons licence and your intended use is not permitted by statutory regulation or exceeds the permitted use, you will need to obtain permission directly from the copyright holder. To view a copy of this licence, visit http://creativecommons.org/licenses/by/4.0/. 


\section{Introduction}

\section{Background and current state of the art}

The protection of underground civil infrastructure continues to be a high priority for transportation and security agencies. In particular, rail transit tunnels running under bodies of water or large-diameter pipes are susceptible to disruptions due to flooding originated by extraordinary climatic events such as hurricanes or human-made events [1-8]. Some examples of such incidents in the United States include the 1992 Chicago freight tunnel flood [9], which forced the shutdown of the subway system, caused damage to numerous businesses, and required the evacuation of about 250,000 people from the area. In 2003, Hurricane Isabel caused flooding of the Midtown Tunnel in Virginia. During this event, more than $167,000 \mathrm{~m}^{3}(\sim 44$ million gallons $)$ of water from the Elizabeth River flooded the tunnel system in just $40 \mathrm{~min}$. The flooding left the tunnel damaged and closed for nearly a month [10]. In 2012, in New York City, seven subway tunnels under the East River, as well as three road tunnels, flooded during Hurricane Sandy and remained inoperable for several days [11-14]. These relatively new incidents and others that occurred in the past decades, such as fires that occurred in different tunnels across the world [2, 15-17] have demonstrated the need for planning and researching ways to mitigate vulnerabilities or, at least, minimize the consequences of catastrophic events.

Although it is impossible to prevent all situations that can lead to flooding, damage can be substantially minimized by reducing the area affected by the event. To mitigate the effects of any eventual threat, a possible approach is to compartmentalize the tunnel system. However, it can be difficult, if not impossible, to install or repair in an existing tunnel all the elements required for compartmentalization. Typically, space constraints inhibit the installation of new protective devices such as automatic or manually operated mechanical gates. The elevated cost of interrupting the tunnel operations or making major infrastructure modifications have also discouraged attempts to improve the tunnel resilience by these means.

The concept of compartmentalization of the tunnel led to the development of different solutions to seal tunnel segments susceptible to an extreme event such as a fire. Inflatable plugs have been used in underground coal mine firefighting as well as in mine rescue operations [18-20]. In these applications, an inflatable feed-tube partition was used to rapidly block large openings, such as underground passageways, and simultaneously provide a feed-tube for high-expansion foam generators. Flooding of mines is not unusual during or after the end of mining activities [21]. For example, a large scale inflatable was used for flood containment in an undeveloped uranium mine in Canada in 2009 [22]. Large-scale inflatable dams for flooding control have also been proposed and implemented in the past years [23-28], but these inflatable structures are built with thick rubber materials, are not flexible, cannot be moved quickly, and are not particularly suitable for confined spaces such as tunnels and large-diameter pipes.

Large inflatable sluice gates for firefighting in transportation tunnels were proposed in 2002. The idea was that "by dividing the tunnel into compartments and providing each compartment with sluice gates, the fire can be isolated, and by lack of oxygen, the fire will not stir up or even extinguish itself" [29]. Based on this concept, in 2008, a fire extinguishing system for tunnel fires was successfully tested in the new Hubertus Tunnel in The Hague, Netherlands [30]. Flooding of transportation tunnel systems is a problem in Asia too. Several studies were recently conducted in China and South Korea to assess flooding risk [31] and to develop small-scale inflatable systems [32-36]. Other similar and more recent efforts in Europe include the INFLATER project [37], also the inflatables developed in Spain [38, 39] and Germany [40] for creating flood barriers of virtually any length along a body of water or other surface-related flood hazards, but not for flooding events in confined environments such as tunnels.

A survey of the current methods used to seal tunnel segments or tunnel portals is presented in Table 1. The existing systems include vertically sliding floodgates, automated or manual doors, portable bulkheads and stop logs. Table 1 provides a summary of a basic description of operation, order-of-magnitude cost of implementation, as well as advantages and disadvantages with respect to the current knowledge and development of large-scale inflatables for tunnel protection.

All the examples listed previously demonstrated the potential of using mid- to large-scale inflatable structures for different containment purposes and isolated events. However, there are no reports in the literature of systematic efforts to develop and implement large-scale inflatables as a protection system in transportation tunnels, either railway or vehicular tunnels, that may be subject to emergencies involving containment of floodwaters. The objective of this work is to provide a review of the development of large-scale inflatables for the protection of transportation railway tunnels against flooding.

\section{Resilient tunnel plug (RTP) project}

The RTP Project started in 2007 to assess the feasibility of developing a rapidly inflatable plug system for plugging tunnels (particularly transit and rail tunnels) in the event of emergency conditions. The overall objective of the RTP Project was to develop and transition an innovative and effective new technology for a rapidly inflatable tunnel plug that can be installed as an 
Table 1 Current technology used for flooding containment in transportation tunnels $[2,41]$

\begin{tabular}{|c|c|c|c|}
\hline System & Description of operation & Order-of-Magnitude Cost (\$US) & Advantages \\
\hline $\begin{array}{l}\text { Sliding } \\
\text { Floodgates }\end{array}$ & $\begin{array}{l}\text { Similar to sliding gates used for } \\
\text { controlling flow in open } \\
\text { channels. }\end{array}$ & $\begin{array}{l}\text { High }(\mathrm{H}) \text {, between } \$ 3 \text { million } \\
\text { and } \$ 10 \text { million, to Very High } \\
(\mathrm{VH}) \text {, over } \$ 10 \text { million }\end{array}$ & $\begin{array}{l}\text { - They are typically made of } \\
\text { steel, which allows } \\
\text { withstanding relatively } \\
\text { medium to high flooding } \\
\text { pressures. } \\
\text { - Typically installed close or } \\
\text { outside of a tunnel entrance. } \\
\text { - These can also be installed in } \\
\text { new tunnels at specific } \\
\text { locations. } \\
\text { - Mechanically or manually } \\
\text { operated. } \\
\text { - With proper maintenance, a } \\
\text { long operative lifetime is } \\
\text { expected. } \\
\text { - Relative quick deployment (< } \\
10 \text { min). }\end{array}$ \\
\hline
\end{tabular}

Automated These are typically designed to Doors protect the tunnel against flooding when fully closed.
Very High $(\mathrm{VH})$, over $\$ 10$ million

Doors can be heavy (see for example the 50,000-lb steel floodgates and other controls at the Hugh L. Carey and Queens Midtown tunnels in New York.

- They are typically made of steel, which allows withstanding relatively medium to high flooding pressures.

- Typically installed close or outside of a tunnel entrance.

- These can also be installed in new tunnels at specific locations.

- Mechanically or manually operated, and with proper maintenance, a long operative lifetime.

- Relative quick deployment (< $10 \mathrm{~min}$ ).

Portable Bulkheads

Similar to automated doors, but with doors stored off-site and installed when needed. Holding frames can be preinstalled in the tunnel.

Medium (M), between $\$ 1$ million $\cdot$ Reactive flood control system and $\$ 3$ million potentially used as a backup system in case of faulty or failure of automated doors. - Portable modules can be transported or craned to the site and installed in preexisting frames to provide a seal.

- Typically installed with cranes or gantries manually operated. - Off-site storage reduces space requirement in the tunnels.

- Slow deployment due to transportation to and installation on the site.

Stop Logs Individual bars or logs combined typically in the vertical direction to make a seal. Holding frames can be preinstalled at entrances or portals or specific locations within the tunnel.
Low (L), up to \$1 million

- Similar to portable bulkheads, it is typically a reactive flood control system.

- Can be used as a backup system in case of faulty or failure of automated doors.

- Relative low-cost alternative.

- Slow deployment due to transportation to and installation of logs on the site.

- Can be used in the proximity of tunnel entrances or within
Disadvantages

- It is challenging to install within existing tunnels without significant disruptions in the tunnel and surrounding areas.

- Significant vertical clearances needed for the installation of floodgates.

- Installation cost in existing tunnels can be high to very high.

- Extensive tunnel utility relocation.

- Maintenance required to ensure operability of mechanisms and prevention of corrosion.

- Installation cost in existing tunnels can be very high.

- Better suited for installation at the entrance of vehicular tunnels with rectangular or square cross-sections but not for circular or quasi-circular cross-sections.

- Maintenance required to ensure operability of mechanisms and prevention of corrosion.

- Limited accessibility to the tunnel during a flooding event can make installation of modules difficult.

- Supporting frames need to be pre-installed and maintained to ensure an adequate sealing capacity.

- Manual assembly may be required at the site.

- Manual assembly may be required at the site.

- Supporting frames may need to be pre-installed at specific locations.

- Holding pressure depends on the material of logs, wood, metal, and concrete.

- Sealing may not be watertight.

- Requires retrofitting of tunnel location for mounting the plug 
Table 1 Current technology used for flooding containment in transportation tunnels [2, 41] (Continued)

\begin{tabular}{|c|c|c|c|c|}
\hline System & Description of operation & Order-of-Magnitude Cost (\$US) & Advantages & Disadvantages \\
\hline & $\begin{array}{l}\text { pre-folded inflatable in a com- } \\
\text { pact container installed at se- } \\
\text { lected locations inside the } \\
\text { tunnel. An air inflation system } \\
\text { deploys and pressurizes rapidly } \\
\text { the inflatable to prevent the } \\
\text { propagation of flooding. }\end{array}$ & $\begin{array}{l}\text { and } \$ 3 \text { million, depending on } \\
\text { the tunnel configuration and } \\
\text { level of retrofitting needed to } \\
\text { install the plug containers }\end{array}$ & $\begin{array}{l}\text { the tunnel system at selected } \\
\text { locations. } \\
\text { - Can be used to } \\
\text { compartmentalize the tunnel } \\
\text { system in segments for } \\
\text { localized flood control. } \\
\text { - Can be installed on the ceiling } \\
\text { or laterals of the tunnels. } \\
\text { - Scalable and modular system } \\
\text { that can be used to contain } \\
\text { flooding in rail, automotive } \\
\text { and other tunnels. } \\
\text { - Current membrane technology } \\
\text { allows containment of } \\
\text { medium flooding pressures, up } \\
\text { to } 100 \text { kPa to } 180 \text { kPa, in } 4 \text { to } \\
6 \text {-m diameter rail tunnels. } \\
\text { - A relatively low-cost system } \\
\text { when compared to automated } \\
\text { doors or vertical flood gates. } \\
\text { - Relative quick deployment (< } \\
5 \text { min) and pressurization (< } \\
20 \text { min). } \\
\text { - When in storage and not in } \\
\text { use, lifetime estimated to be } \\
\text { around } 15 \text { to } 20 \text { years. }\end{array}$ & $\begin{array}{l}\text { container and also to maximize } \\
\text { the sealing capacity of the } \\
\text { inflatable. } \\
\text { - The structural membrane of } \\
\text { the inflatable may be } \\
\text { susceptible to abrasion in } \\
\text { rough tunnel environments. } \\
\text { - Current materials and } \\
\text { manufacturing technology } \\
\text { prevent reaching higher } \\
\text { inflation pressures, which in } \\
\text { turn limit the flooding } \\
\text { pressures that can be } \\
\text { contained. } \\
\text { - Once used in a flooding event, } \\
\text { the inflatable and container } \\
\text { need to be replaced by a new } \\
\text { or refurbished unit. }\end{array}$ \\
\hline
\end{tabular}

alternative means to seal underground tunnels to prevent flooding originated by massive storm surges, hurricanes or extraordinary human-made events. Such technology could provide a more flexible solution than traditional floodgates in certain instances, particularly for application in existing tunnels with ongoing operations that limit and complicate construction and installation activities. By working with potential end-user organizations, the project focused on developing a system that could meet the full range of real-world requirements to be installed in working railway tunnels in operational rail systems. The interaction with end-user organizations also facilitated the effective transition of the technology for implementation in their systems. The project evolved in phases, as follows: Phase 1 - Proof of Concept (2007-2008); Phase 2 - Single-Layer Plug (2009-2010); Phase 2b - Multi-Layer Plug (2011-2012) and; Phase 2b - Multi-Layer Plug, Extended Testing (2012-2013); and Phase 3 - Prototype Integrated System (2013-2017).

Conceptually, the RTP system consists of an inflatable plug comprised of a cylindrical portion with two hemispherical end-caps which can be stored until needed inside a tunnel in a suitable container to protect it from the tunnel environment. On command, a control system deploys the plug from its storage container, inflates the plug and maintains it at a suitable inflation pressure for the required time. The plug can be pressurized with either air or water, depending on the specific application, to a demand that exceeds the anticipated pressure of floodwaters by an appropriate safety factor. A schematic representation of the RTP system is illustrated in Fig. 1.

The reference parameters used for design and testing of the RTP system presented in this work included a nominal tunnel diameter in the range of 5 to $6 \mathrm{~m}$ (16 to $20 \mathrm{ft}$ ), and deployment and pressurization time in the range of 10 to $20 \mathrm{~min}$. In this time, the plug should be able to be fully pressurized with internal pressure in the range of 100 to $180 \mathrm{kPa}$ ( $\sim 14$ to $26 \mathrm{psig}$ ), to withstand a flooding pressure in the range of 80 to $100 \mathrm{kPa}(\sim 11$ to $\sim 15$ psig) while remaining stable and operational for at least 3 weeks.

\section{RTP key technical challenges}

During the development of the different phases of the RTP Project, several key technical challenges had to be met before the completion of the project to provide a successful inflatable plug system for rapid response in tunnels. Each of the technical challenges required the definition of an approach adopted to meet them. The approaches selected for addressing the different challenges contributed to defining the basic logic underlying the system requirements, which ultimately drove the technology development and also helped to shape the testing that was required to move from one phase of the project to the next. The most significant technical challenges faced by the RTP Project included:

a) Strength: The inflatable plug, and by extension the support systems, must have sufficient strength to withstand the forces involved, of which the most 


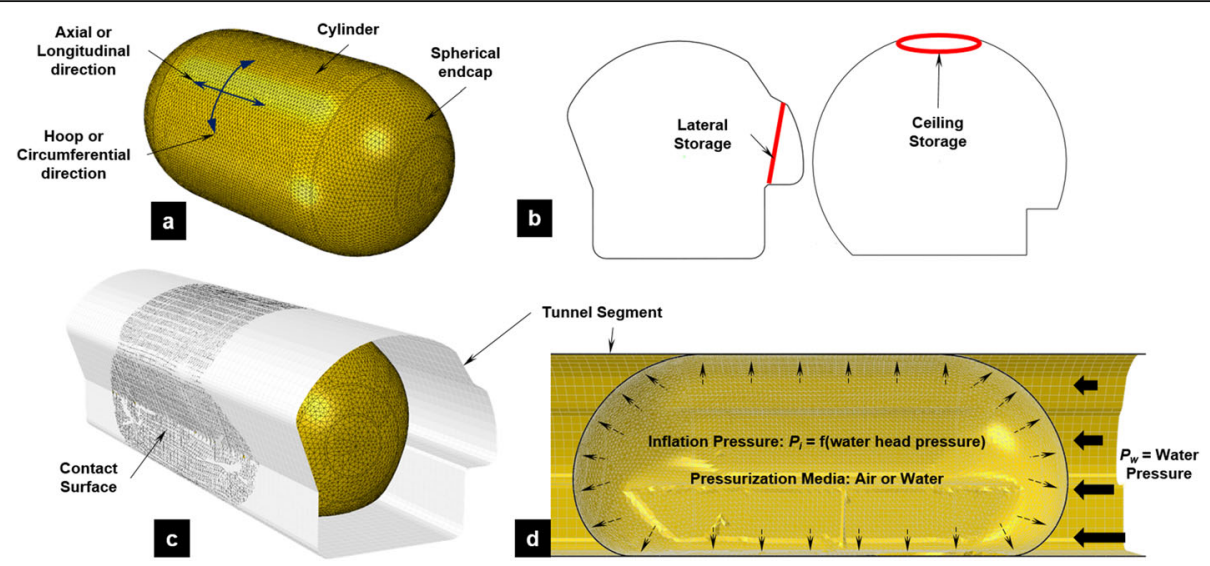

Fig. 1 A conceptual overview of the RTP System: a Inflatable plug, unconfined configuration; b Tunnel profiles and folded plug storage areas; $\mathbf{c}$ Inflatable plug deployed and inflated in the tunnel (confined configuration); d Longitudinal cross-section, inflation and flooding pressures [42-47]

challenging is potential tunnel flooding. To be able to establish and maintain an effective seal, the inflated plug must have sufficient strength to withstand stresses associated both with internal pressures needed to inflate the plug and anchor it in place against the tunnel walls, and with external forces acting against the plug (such as the pressures of floodwaters). It must also be able to withstand localized stresses resulting from impingement points against tunnel geometry or equipment. Also, this strength must be built into the system in a way that is consistent with the need to be able to fold the plug compactly into a storage container with limited volume, thus requiring relatively thin-wall, pliable construction. The potential for water flooding is the most demanding on system design and capabilities, so flooding has been used as the design basis for this technical challenge. The required plug strength was based on material selection, plug design, plug construction, and compact storage constraints.

b) Storage Space: The plug and the associated support systems must be capable of being stored in a compact limited area in an actively used tunnel until needed, without impeding regular traffic. However, tunnels such as those used by transit agencies have limited free space and have a variety of different equipment and utilities that support the ongoing operation of the tunnel system. Many of these supporting systems were installed after the tunnels were designed and built, and their subsequent installation has contributed to the lack of space in the tunnels. Furthermore, it is nearly impossible to rebuild tunnels to provide additional space. Given these space limitations and to avoid interference with the operation of passing traffic, the plug module (i.e., the stored plug and the container within which is it stored) must fit into a very tight space defined by tunnel geometry and the "dynamic envelope" of the traffic themselves.

Moreover, passing trains exert pressure waves that depend on the speed of the moving convoy. The effect of the pressure waves needs to be taken into account to prevent pressure waves from damaging the storage container or triggering accidental activation and deployment of the inflatable plug. Some examples of the determination of the pressure waves in rail tunnels can be found in the studies reported in $[48,49]$. Other support systems (e.g., the inflation and control systems) also need to fit into available space without interfering with normal operations within the tunnel. It is possible to relocate or otherwise change some of the other systems installed in the tunnel, to accommodate the plug module, but such modifications are still limited by a variety of other considerations. Thus, the plug module must be highly compact. To achieve this, the plug itself must be highly flexible and foldable to minimize storage space and, at the same time, allow effective deployment when needed.

c) Sealing Capability: Once deployed and inflated, the plug must be capable of providing a sufficient seal within the working tunnel environment, which includes other systems and utilities that could interfere with sealing, to reduce leakage to an allowable amount. The sufficiency of the sealing ability depends on the specific condition being considered and the ability of the existing tunnel infrastructure to handle potential leakage. For example, in an emergency event involving a gas release, the sealing ability must sufficiently contain the release to allow the tunnel ventilation system to remove the released gases and keep them from spreading within the tunnel system. For a flooding 
incident, the seal must sufficiently reduce the flow of water to a flow rate that can be handled by pumps located further along the tunnel and must limit the depth of water near the plug to allow possible recovery efforts to proceed. As indicated previously, a threat of water flooding is the most demanding on system design and capabilities due to the hydrostatic head pressure; and flooding has been used as the design basis for this project. The ability to obtain a sufficient seal against the tunnel surfaces can be reduced by factors such as the basic geometry of the tunnel and irregularities in the tunnel surface, utilities and other equipment installed in that portion of the tunnel, and the positioning of the plug during deployment. Transit tunnels typically contain tracks, pipes, vents, lights, and other utilities, and most tunnels also include a raised service walkway on at least one side. Considering the obstacles present in tunnels and to ensure a good seal, the plug systems will need to be installed in prepared sections of the tunnel that are "groomed" to improve the plug's ability to conform both globally and locally to the tunnel geometry for an effective seal. Other tunnel equipment may be removed from that relatively short section of tunnel, and piping and cables may be bundled and encased within enclosures to provide an improved surface contour against which the plug can seal more effectively.

d) Integration: The inflatable plug and associated support systems must effectively interface with normal tunnel operations and operational constraints, as well as regulatory restrictions (such as fire protection and building codes) without requiring significant exceptions to standard operational protocols and procedures. The concept of modularizing the inflatable plug and container in a single unit that can be installed or replaced within normal routine maintenance periods as needed was adopted to simplify the interface with the tunnel and existing systems. Some modifications to current operational and maintenance practices might be expected to accommodate the new system and associated supporting utilities to fully integrate it to the existing features of the tunnel.

e) Tunnel Environment: The plug and the associated support systems must remain unaffected by the tunnel environment to ensure operability when needed. By its very nature, a system such as the RTP system, once installed, will remain in storage within the tunnel in a ready state until it needs to be deployed and inflated in response to an incident. Thus, to perform effectively when needed, the various system components must be able to withstand the tunnel environment over long periods before deployment. The tunnel environment conditions can be particularly harsh. Tunnels are subjected to fluctuations in ambient temperature, high humidity, and copious quantities of dust from wear on the brakes and wheels of the vehicles, pressure and suction pulses generated by the passage of vehicles, stray electrical currents around the high-power third-rail train systems, vermin, and possible saline conditions. These environmental conditions need to be considered for material selection and component manufacturing, installation practices and operation to provide long-term resistance to environmental degradation. Structurally, and regardless of the fluid used for pressurization of the inflatable (typically compressed air or water), the inflation pressure is transferred, at the contact area, to the primary liner system of the tunnel. The integrity of the liner will require verification of its pressure-bearing capacity. Mid-size rail tunnels, with circular or near-to-circular cross-sections, with diameters in the range of 5 to $7 \mathrm{~m}$, running under bodies of water such as channels, rivers, and bays, can have different types of liners depending on the kind of ground that surrounds the tunnel. Materials typically used for the primary liner system include fabricated steel, cast iron, cast-in-place concrete, and precast concrete segmental liners [50-52]. The liner is typically comprised of circular segments assembled to form rings. The stability of the rings created by the segments derives from the contact and the support provided by the surrounding ground $[53,54]$. Additional technological details regarding tunnel liners can be found in [55-68] and considerations for their integrations with inflatable plugs can be found in [69].

f) Long-Term Reliability: Ultimately, the inflatable tunnel plug system must provide a very high degree of reliability to ensure effective operation even after a long period of storage, without complicated maintenance requirements. Responding to this challenge requires attention in all areas of the project, including materials selection and testing; equipment selection, design and fabrication; prototype testing and analysis; and system modeling to anticipate unforeseen situations that could be mitigated in advance. It also requires a thorough evaluation of the interface with existing operations and equipment installations to identify potential failure mechanisms and ensure the system design provides adequate protection against them.

\section{Inflatable plug design considerations}

The potential for water flooding was deemed the most demanding on system design and capabilities and was 
used as the design basis for the inflatable plug. To ensure that the inflatable plug performs adequately and appropriately, three design conditions must be satisfied. Failure of any one of these conditions during operation would result in the overall failure of the system. Furthermore, it is noted that these are not independent factors and need to be balanced as a system to achieve a functional plug design. These conditions, introduced by Martinez et al. (2012) [42] and explained in detail by Barbero et al. (2013) [43, 44], are summarized as follows:

1) Inflation Pressure: Sufficient inflation pressure needs to be achieved and maintained on the inflatable plug to keep its shape geometrically stable. The inflation pressure must be higher than the upstream external flooding pressures that could be encountered by the system in the particular location where the plug is installed. The critical variable that needs to be defined is the maximum water depth for possible floodwaters at the site of interest.

2) Structural Strength of the Inflatable Plug: The membrane of the inflatable plug must have sufficient structural strength to withstand: 1) the inflation pressures under working conditions, and 2) any additional concentrated local stresses caused by bridging of the membrane around or over variations and irregularities in tunnel geometry (e.g., at corners of duct banks). The key variables available to control these two demands are the strength of the materials used in the plug construction and the specific geometric design and manufacturing technique selected to build the plug.

3) Friction Resistance of the Plug against the Tunnel Walls: The surface of the inflatable plug in contact with the inner tunnel surface must provide sufficient frictional resistance against the tunnel walls to remain in place against the maximum potential flooding pressures. Satisfying this condition assures the stability of the plug while being subject to the flooding pressures. Key variables that determine this ability include: 1 ) frictional properties of the outer layer of the plug; 2) frictional properties of the tunnel surface against which the plug inflates; 3) plug inflation pressure (minimum plug inflation pressure already a factor defined above); 4) plug length impinging against the tunnel surfaces, and 5) sufficient plug oversizing (ratio of plug circumference to tunnel perimeter) to ensure plug contact with the tunnel surfaces.

\section{Results of experimental evaluations Phase 1: proof of concept}

The initial phase of the RTP Project started in 2007 and continued through late 2008. Phase 1 focused on providing a proof of concept, with sufficient fidelity to evaluate the inflatable tunnel plug concept for further development. The concept development and testing during Phase 1 were focused primarily on the plug. Initial work was also done to begin to understand the needs and options for the other system components. The initial prototypes were designed to be manufactured with a single layer fabric subject to a relatively low air inflation pressure $(7 \mathrm{kPa})$. This initial design required research and testing activities in the following three main areas:

a) Material Testing: Tensile strength and frictional characteristics were determined at the coupon level for candidate fabric materials used in other types of inflatable structures. Tensile testing of as received and welded fabric specimens contributed to determining the most suitable fabric for the initial prototypes. Polyester with flexible PVC composite coating was selected as fabric material for the manufacturing of initial prototypes. Friction tests reproduced the contact interaction between the surfaces of a concrete tunnel liner rubbing against fabric materials. Ways to increase the frictional forces were tested as well by implementing different coatings applied to concrete specimens rubbing against fabric specimens as reported in Molina (2008) [70].

b) Reduced Scale Prototype Testing: Phase 1 included small-scale testing of several different plug designs in a transparent scale model (1:5.7) of a transit tunnel to observe deployment and inflation of the plug and to support leakage testing. Tests were conducted at a low air pressure $(2 \mathrm{kPa})$ and served to gather an initial understanding of folding and placement of the inflatable in the tunnel as well as the dynamics of the deployment from the ceiling of the tunnel profile as shown in Fig. 2.

c) Full-Scale Prototype Testing: A single-layer, lowpressure, low-strength prototype plug with a fitted plug geometry was constructed to mimic a typical tunnel profile. The fitted geometry was chosen to better conform to the tunnel cross-section and to help achieve a better seal between the plug and the tunnel. Initial folding, mounting, deployment, and inflation tests were conducted in a simplified tunnel geometry mockup that served as a preparation for a subsequent full-scale demonstration inside an actual transit tail tunnel at the end of a transit system line. The testing was conducted at a low inflation pressure of $7 \mathrm{kPa}$ and without any water flooding, but leakage testing using smoke was used to demonstrate the ability to seal the tunnel area. This initial phase also validated that a plug module could be installed in a tunnel in limited time windows, an 


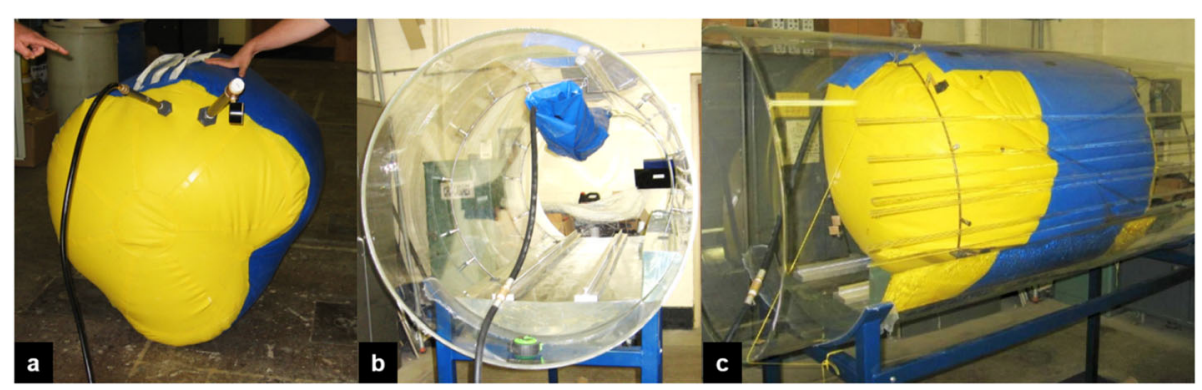

Fig. 2 Phase 1, reduced-scale testing: a Unconfined inflation of 1:5.7 prototype; b Folded plug ready for deployment in acrylic tunnel mockup; $\mathbf{c}$ Inflation in the acrylic tunnel

important consideration for future adoption by tunnel operators [42]. It is important to note that the initial prototypes used for the proof of concept and both at reduced and full-scale evaluations were neither designed nor built with sufficient strength to hold back floodwater, so no water testing was included in Phase 1.

The results of Phase 1 were sufficiently promising to provide the basis for further development. Test results showed that a full-scale initial prototype plug could be successfully installed in a tunnel within a regular overnight work shift [42]. The tests in an actual tunnel section also demonstrated that the folded inflatable plug could be successfully installed within space allotted outside of the dynamic envelope of any rail cars and be successfully deployed and inflated within a specified period. Figure 3 shows the sequence of initial deployment and inflation during the proof of concept test [42]. Smoke testing indicated a reasonable seal between the plug and the tunnel walls and floor. Although existing utility lines and piping along tunnel walls and ceiling created some pathways for leakage, results indicated that for actual application and future testing, such lines and piping would have to be moved or otherwise covered to minimize these leakage pathways. A summary of the key features of the inflatable, objectives, and results from Phase 1 is presented in Table 2.

\section{Phase 2: single layer membrane design}

Based on the results obtained during Phase 1 of the project, Phase 2 commenced at the beginning of 2009 and continued until the end of 2010. Phase 2 focused on the development of a single-layer fitted plug design to meet the requirements for applications involving intermediate pressure levels, leading to a plug constructed of highstrength Vectran fabric [71]. Phase 2 focused on the development and testing of prototypes at both quarter scale and full scale, to serve different testing purposes and to validate performance. Phase 2 also included significant materials testing to verify the properties of the materials and provide a basis for modeling and analysis. To support the development and testing objectives for Phase 2 (and for subsequent phases), a testing apparatus needed to be established. This included the design and construction of a quarter-scale test setup and a full-scale

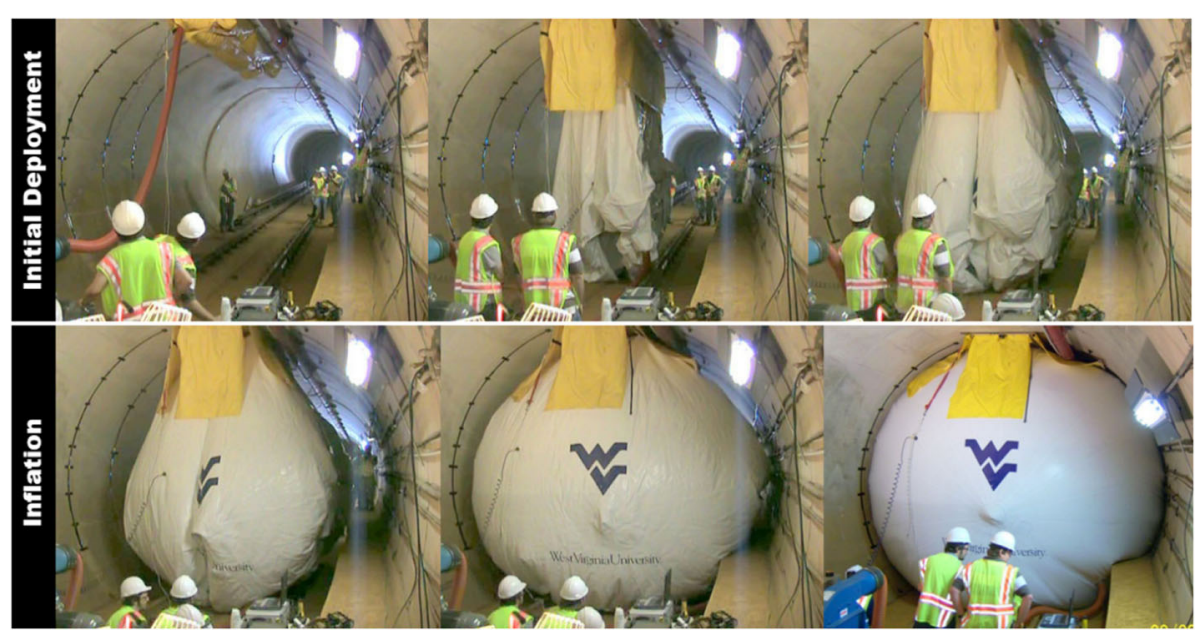

Fig. 3 Phase 1, full-scale testing, proof of concept in actual railway tail tunnel [42] 
Table 2 Summary of key parameters, objectives, and main results obtained from each phase

\begin{tabular}{|c|c|c|}
\hline hase & $\begin{array}{l}\text { Key Inflatable Plug } \\
\text { Features }\end{array}$ & Testing Objectives \\
\hline $\begin{array}{l}\text { Phase } \\
1: \\
2007- \\
2008\end{array}$ & $\begin{array}{l}\text { - Fitted plug } \\
\text { geometry } \\
\text { - Low-strength } \\
\text { material } \\
\text { - Low-pressure air } \\
\text { inflation only }\end{array}$ & $\begin{array}{l}\text { - Demonstrate installation and storage } \\
\text { outside of the dynamic envelope. } \\
\text { - Demonstrate adequate deployment time. } \\
\text { - Demonstrate the ability to obtain } \\
\text { acceptable tunnel seal. } \\
\text { - Establish working relationships with } \\
\text { potential end-user organizations. }\end{array}$ \\
\hline
\end{tabular}

\begin{tabular}{|c|c|c|}
\hline $\begin{array}{l}\text { Phase } \\
2: \\
2009- \\
2010\end{array}$ & $\begin{array}{l}\text { - Fitted plug } \\
\text { geometry } \\
\text { - High-strength, } \\
\text { single-layer } \\
\text { material } \\
\text { - Full-pressure } \\
\text { water inflation } \\
\text { against floodwa- }\end{array}$ & $\begin{array}{l}\text { - Design and construction of full-scale } \\
\text { pressure-capable testing apparatus. } \\
\text { - Demonstrate deployment time to full } \\
\text { pressure. } \\
\text { - Demonstrate the ability to achieve } \\
\text { acceptable tunnel seal under pressure. } \\
\text { - Identify the advantages and limitations of } \\
\text { single-layer plug design. }\end{array}$ \\
\hline
\end{tabular}
ter pressure

\author{
Test Scale / Location / Main Results \\ Validation \\ Reduced scale (1:5.7) Understanding of deployment dynamics. \\ Laboratory see- $\quad$ Several trials with different plug shapes \\ through scale model demonstrated the sealing capacity of each \\ Inspection and smoke shape. \\ testing

\section{Full scale \\ Laboratory tunnel \\ mockup \\ Inspection and timing} \\ Full scale \\ Transit rail tunnel \\ Inspection, timing, \\ and smoke testing \\ Reduced scale (1:4) \\ Quarter-scale testing \\ apparatus \\ Inspection and \\ pressurized water \\ testing \\ Full-scale surrogate \\ Full-scale tunnel \\ mockup \\ Inspection and timing \\ Full-scale Vectran \\ fabric \\ Full-scale tunnel \\ mockup \\ Inspection, timing, \\ and pressurized water \\ testing \\ Installation procedures demonstrated; \\ deployment timing established. \\ Installation completed within established time \\ and space requirements; deployment within \\ the required time; indication of ability to \\ achieve an adequate seal. \\ Frictional properties adequate to withstand \\ flooding water pressures with an acceptable \\ leakage rate. \\ Installation procedures demonstrated; \\ deployment timing established. \\ Acceptable deployment; sizing established for \\ final Phase 2 full-scale plug. \\ Frictional properties proved to withstand \\ flooding water pressures, but the strength of \\ single-layer material found to be insufficient to \\ withstand full pressurization.
}

$\begin{array}{lll}\text { Phase } & \text { - High-strength, } & \text { - Demonstrate the ability of the cylindrical } \\ \mathbf{2 b :} & \text { multi-layer } & \text { plug to conform to tunnel geometry. } \\ \mathbf{2 0 1 1 -} & \text { material } & \text { - Demonstrate the ability to handle a } \\ \mathbf{2 0 1 2} & \text { - Cylindrical plug } & \text { heavier, thicker membrane construction } \\ & \text { geometry } & \text { while improving plug deployment and } \\ & \text { - Full-pressure } & \text { sealing characteristics. } \\ & \text { water inflation } & \text { - Demonstrate the ability to achieve } \\ & \text { against floodwa- } & \text { acceptable tunnel seal under pressure. } \\ & \text { ter pressure } & \text { - Remain stable under water flooding } \\ & & \text { pressure. }\end{array}$

Full-scale surrogate

Full-scale tunnel

mockup

Inspection, timing,

and smoke testing

Quarter scale

Quarter-scale testing

apparatus

Inspection and

pressurized water

testing

Full scale

Full-scale tunnel

mockup

Inspection, timing,

and pressurized water

testing

\begin{tabular}{|c|c|c|}
\hline $\begin{array}{l}\text { nase } \\
\text { o-ET: } \\
012- \\
013\end{array}$ & $\begin{array}{l}\text { - High-strength, } \\
\text { multi-layer } \\
\text { material } \\
\text { - Cylindrical plug } \\
\text { geometry } \\
\text { - Full-pressure } \\
\text { water inflation } \\
\text { against floodwa- } \\
\text { ter pressure }\end{array}$ & $\begin{array}{l}\text { - Integrate plug with a modular, soft-pack } \\
\text { container for improved installation } \\
\text { characteristics. } \\
\text { - Demonstrate repeatability of successful } \\
\text { plug deployment and plug conformity to } \\
\text { provide adequate tunnel seal. } \\
\text { - Evaluate the impact of changes in plug } \\
\text { oversizing ratio. } \\
\text { - Establish a range of acceptable leakage } \\
\text { rates measured during full-scale flooding } \\
\text { simulations. }\end{array}$ \\
\hline
\end{tabular}

Full-scale surrogate

Full-scale tunnel

mockup

Inspection and

contact sensors,

timing

Full scale

Full-scale tunnel

mockup

Inspection and

contact sensors,

timing, and

pressurized water testing
Acceptable deployment; sizing established for final Phase $2 b$ large-scale plug.

Frictional properties adequate to withstand flooding water pressures with an acceptable leakage rate and no slippage.

Frictional properties have proven to withstand flooding water pressures with an acceptable leakage rate and sufficient plug strength.

Repeatable, acceptable deployment and conformance to tunnel geometry.

Repeatable, acceptable deployment and conformance to tunnel geometry, ability to withstand floodwater pressures with acceptable leakage rate and sufficient plug strength. 
Table 2 Summary of key parameters, objectives, and main results obtained from each phase (Continued)

\begin{tabular}{|c|c|c|c|c|}
\hline Phase & $\begin{array}{l}\text { Key Inflatable Plug } \\
\text { Features }\end{array}$ & Testing Objectives & $\begin{array}{l}\text { Test Scale / Location / } \\
\text { Validation }\end{array}$ & Main Results \\
\hline & & & $\begin{array}{l}\text { Quarter scale } \\
\text { Quarter-scale testing } \\
\text { apparatus } \\
\text { Inspection and } \\
\text { pressurized water } \\
\text { testing }\end{array}$ & $\begin{array}{l}\text { Tradeoffs in plug frictional and sealing } \\
\text { properties with adjustments in plug oversizing. }\end{array}$ \\
\hline $\begin{array}{l}\text { Phase } \\
3: \\
2013- \\
2017\end{array}$ & $\begin{array}{l}\text { - Refined } \\
\text { prototype plug } \\
\text { and container } \\
\text { - An automated } \\
\text { prototype } \\
\text { inflation system } \\
\text { - Full-pressure air } \\
\text { inflation against } \\
\text { floodwater } \\
\text { pressure }\end{array}$ & $\begin{array}{l}\text { - Move tunnel mockup to the plug } \\
\text { manufacturer location for full-pressure air } \\
\text { inflation testing. } \\
\text { - Modify tunnel configuration to a } \\
\text { representative configuration. } \\
\text { - Integrate refined plug and container with } \\
\text { prototype inflation system. } \\
\text { - Demonstrate full-pressure air inflation. } \\
\text { - Demonstrate repeatability of system } \\
\text { performance in prototype configuration. } \\
\text { - Demonstrate long-term system operation } \\
\text { and performance. }\end{array}$ & $\begin{array}{l}\text { Full scale } \\
\text { Relocated, } \\
\text { reconfigured tunnel } \\
\text { mockup } \\
\text { Inspection, timing, } \\
\text { and pressurized } \\
\text { floodwater testing }\end{array}$ & $\begin{array}{l}\text { Reliable deployment and inflation within the } \\
\text { required time; demonstration of the operation } \\
\text { of the fully integrated system; verification of } \\
\text { required frictional and sealing properties. } \\
\text { Demonstration of ability for long-term ( } 21 \text { days) } \\
\text { continuous performance of the system. }\end{array}$ \\
\hline
\end{tabular}

tunnel mockup for testing, which were initially established at West Virginia University (WVU). These testing apparatus allowed tests to be conducted in a more controlled environment with the inflatables subject to different levels of pressurization to contain the pressure of simulated floodwaters behind the plugs. Phase 2 testing incorporated low-pressure air for the deployment and initial inflation of the plug. Testing was also conducted with the quarter and full-scale plugs with water as the internal fluid. Water was also used to simulate the flooding behind the plug. The idea of using a small-scale tunnel was also implemented in $[32,35,36]$ to test friction and stability characteristics, as well as the deployment of small scale inflatables. Similarly to Phase 1, testing activities carried out as part of Phase 2 were focused on the following three main areas:

a) Material Testing: As indicated in Section 1.3, the strength of the membrane material is critical to ensure the ability of the plug to resist the harsh environments of tunnels. Several high-strength aramid synthetic fibers are available for demanding applications, such as resistance to impacts, friction, abrasion and high stresses. Among aramid fibers, Vectran [71] was selected for the construction of high-strength fabrics of the inflatable plug. Vectran is commonly used in aerospace applications where high-strength, high foldability with minimum degradation is required [72-83]. Tests at coupon level included tensile testing, friction testing under dry and wet conditions, crease fold testing, long-term static loading on single and seam specimens, abrasion testing, and flammability of coated specimens.

b) Reduced Scale Prototype Testing: The quarter-scale test setup consisted of a $1.22 \mathrm{~m}(4-\mathrm{ft})$ diameter concrete culvert with one end sealed to allow simulated flood water to be introduced behind the inflated quarter-scale plug. Pumps, plumbing, and control systems were established to allow inflation and pressurization of the quarter-scale plug as well as the introduction of simulated flood water under pressure behind the plug. Pressure sensors and other instrumentation were included to allow monitoring and recording of test conditions as well as accurate control of plug and tunnel pressures. The quarterscale plug was fabricated of the same materials as the final full-scale plug to investigate the performance against flooding pressure in a simplified cylindrical tunnel geometry [84]. The internal water pressure for the quarter-scale setup ranged from 104 to $483 \mathrm{kPa}$ ( 15 to 70 psig), and external flooding pressure ranged from $69 \mathrm{kPa}$ to $345 \mathrm{kPa}$ ( 10 to $50 \mathrm{psig}$ ).

c) Full-Scale Prototype Testing: The full-scale tunnel mockup was a 4.9-m (16-ft) diameter horizontal cylinder, with a domed closure on one end to allow for the introduction of pressurized simulated floodwater behind the plug. This size is representative of the typical size of transit tunnels. Two different plug prototypes were used for full-scale testing: a) a fullscale plug manufactured from a single layer of lessexpensive material, without the strength of the final materials, was used for initial low-pressure testing with air as illustrated in Fig. 4. This plug, referred to as the surrogate single layer plug, was used to investigate plug handling and deployment characteristics, to fine-tune plug fabrication techniques, and to check the sizing of the plug against the tunnel mockup to allow for adjustment in the size of the final plug; b) a full-scale plug manufactured from a single layer of urethane-coated Vectran fabric was 


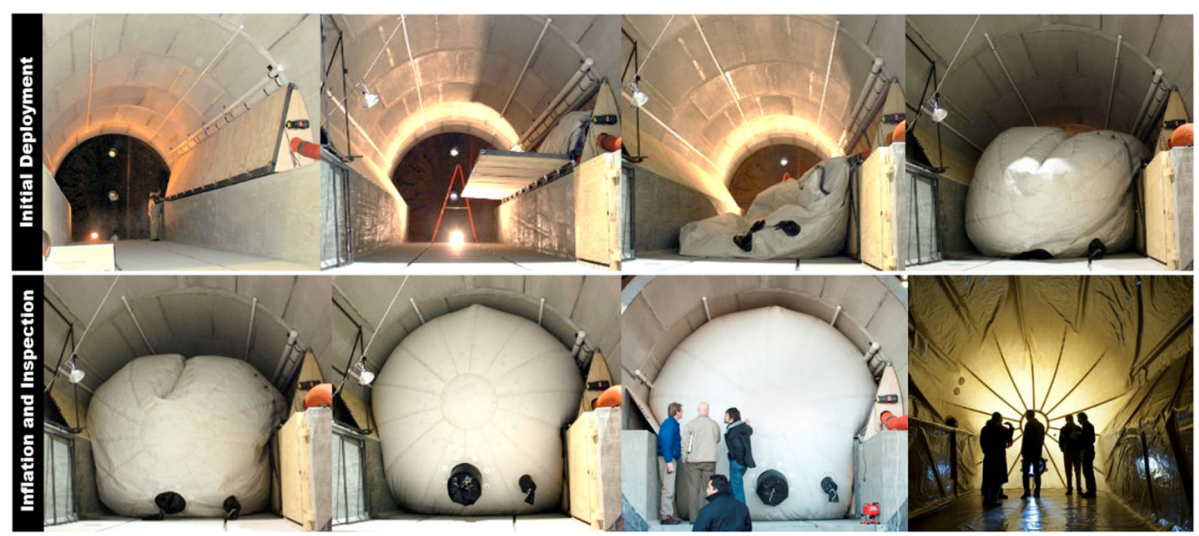

Fig. 4 Phase 2, full-scale testing, single layer surrogate plug: Sequence of initial deployment, inflation, and external and internal inspection

used to test performance at the representative scale and in a tunnel geometry representative of actual transit tunnels. Both full-scale plugs tested during Phase 2 used a fitted design to conform to tunnel geometry and contours. An overview of the key features of the inflatable plug, objectives, and results from Phase 2 is summarized in Table 2.

Phase 2 provided much useful information regarding deployment and initial inflation characteristics, but it culminated with a failure of the full-scale, single-layer Vectran fabric plug. Examination of the plug following the failure indicated that this was a failure of the material itself, and not a construction flaw. Given the strength of the material used for the full-scale plug and the available alternatives, it was ultimately determined that the single-layer design could not be relied upon to provide sufficient strength to meet the design requirements, driving a redesign carried out during Phase $2 \mathrm{~b}$. An overview of key features of the inflatable plug, objectives, and results from Phase 2 is summarized in Table 2.

\section{Phase 2b: multi-layer membrane design, initial testing} The failure of the single-layer plug during Phase 2 required further investigation on alternative configurations of high-strength flexible materials and their mechanical properties. Multilayer membrane designs for inflatable structures developed for aerospace applications working in harsh environments were considered in this phase [75]. The purpose of considering alternative membrane designs was to ensure the ability to successfully deploy a compactly folded plug installed in a tunnel segment, with sufficient strength for repeated handling maneuvers and capable to contain flooding at the reference pressures.

A three-layer concept was ultimately selected to continue the development of the inflatable tunnel plug. It was comprised of the following layers: Layer $1-$ an outer layer of interwoven Vectran webbing material to provide the necessary tensile strength and frictional properties for the plug; Layer 2 - a protective Vectran fabric layer over the bladder layer to prevent damage to the bladder (with sewn seams rather than welded seams to avoid trapping air between the protective layer and the bladder layer); and Layer 3 - an inner bladder layer of urethane-coated polyester material to contain the inflation fluid (but lacking sufficient strength to meet the overall strength requirements for the plug $[85,86]$. The three-layer configuration is illustrated in Fig. 6a. These three layers were indexed together (i.e., connected) at appropriate intervals to ensure that the plug material behaved similarly to a single-layer material and not bind during the folding, packing, or deployment operations. Similarly to Phases 1 and 2, testing activities carried out as part of Phase $2 \mathrm{~b}$ were focused on the following three main areas:

a) Material Testing: Three types of testing were conducted during Phase 2b. 1) Uniaxial tensile tests were used to determine the ultimate tensile strength of specimens of Vectran webbing used to produce the outer layer of the full-scale plug. 2) Friction testing of Vectran webbing was also necessary to determine the plug's ability to maintain axial stability within the tunnel during operation under dry and wet conditions [89]. 3) Shear tests were used to determine the level of shear forces that are present in the draping and flexibility of a macro fabric comprised of Vectran woven webbings and to determine the ability of the material to conform to a three-dimensional surface [90]. Figure 5 summarizes the three types of material testing conducted during Phase $2 \mathrm{~b}$.

b) Reduced Scale and Full-Scale Prototype Testing: Three different types of plugs were fabricated, in sequence, to meet specific testing requirements and provide input to the next phase of design. Each inflatable plug was designed based on materials 
testing results, testing results with the previous plug(s) in the Phase $2 \mathrm{~b}$ series (and also, where applicable, results obtained during Phase 2), and test objectives to be achieved. These three types of plugs are referred to as the quarter-scale plug, the surrogate (full-scale) plug, and the full-scale plug. As in Phase 2, the surrogate plug was a full-size plug made to investigate the full-size three-layer design but fabricated using less-expensive materials, as shown in Fig. 6b. The materials used were chosen to result in a plug with handling characteristics similar to those using the Vectran materials for the final plug illustrated in Fig. 6c. The less-expensive surrogate plug provided an opportunity to check the appropriate fitting of the plug to the size of the test tunnel, allowing adjustment of plug sizing before proceeding with the fabrication of the moreexpensive full-scale plug. Because the less-expensive materials used in the surrogate plug resulted in significantly reduced plug strength, all testing with the surrogate plug was limited to low-pressure air inflation with no testing using water flooding behind the surrogate plug.

The quarter-scale plug was the next in the series to be fabricated and tested. The quarter-scale plug was manufactured from the same materials as the final full-scale plug. Thus, the quarter-scale plug provided for verification of the performance of the final materials before production of the full-scale plug. Testing with the quarterscale plug included an assessment of plug performance against flooding pressure in a simplified (i.e., cylindrical) tunnel geometry. One of the most critical outcomes from quarter-scale testing was the fine-tuning of friction factors assumed in calculating the required length of the cylindrical body of the final full-scale plug. Testing at quarter scale also allowed inducing plug slippage to verify the minimum pressure differential required between the internal plug pressure and the external floodwater pressure; such testing was not conducted at full scale because of the additional time and expense associated with testing plug slippage at that scale and the possibility of damage to the plug [89]. Figure 7 illustrates the quarterscale plug during preparation and flooding simulations.

c) Storage Container: The full-scale surrogate plug was also used as a reference for the design and testing of the storage container that would hold the folded plug until the deployment signal is triggered. In this regard, a parallel approach to container design was taken, including both a hard and soft-pack container options, allowing both types of designs to be tested. Because the development of a hard container option had been initiated during Phase 2, and the soft-pack container was a new option introduced in Phase 2b, the parallel approach also allowed plug testing to proceed using the hard container without waiting for the completion of the soft-pack container. The soft-pack container prototype was then tested with the surrogate and fullscale plugs during the Extended Testing Phase.

Full-pressure water inflation following initial lowpressure air inflation to achieve plug deployment shaping was initiated in Phase 2, and it was further developed and implemented during Phase $2 \mathrm{~b}$. This technique allowed to control the pre-positioning of the inflatable in the tunnel at a relatively low inflation pressure $(7 \mathrm{kPa})$ and to ensure proper levels of global and local conformity of the inflated plug to the tunnel profile before full pressurization.

The ultimate objective of Phase $2 b$ was achieved: a plug, strong enough to contain flooding at the reference design pressures, was successfully deployed and inflated in the mockup tunnel. The three-layer folded plug was installed along a lateral tunnel wall, held inside a container until a deployment signal was activated and then

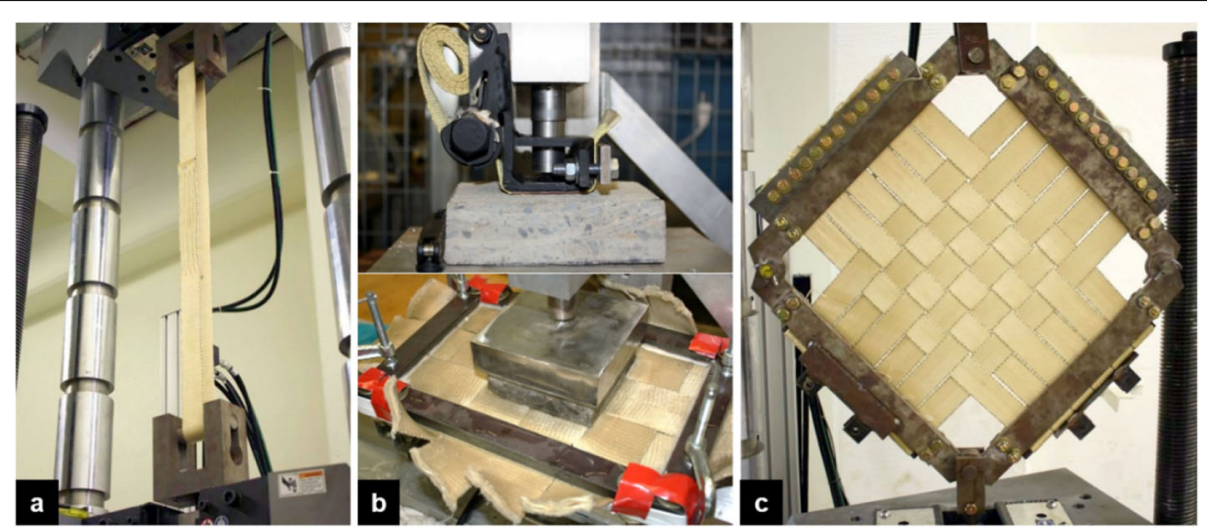

Fig. 5 Phase 2b, material testing: a Tensile test of single loop stitched Vectran webbing; b Friction testing of single Vectran webbing on concrete (top) and friction testing of woven webbings on concrete (bottom) [26]; c Picture frame shear testing of Vectran woven webbing [89, 90] 


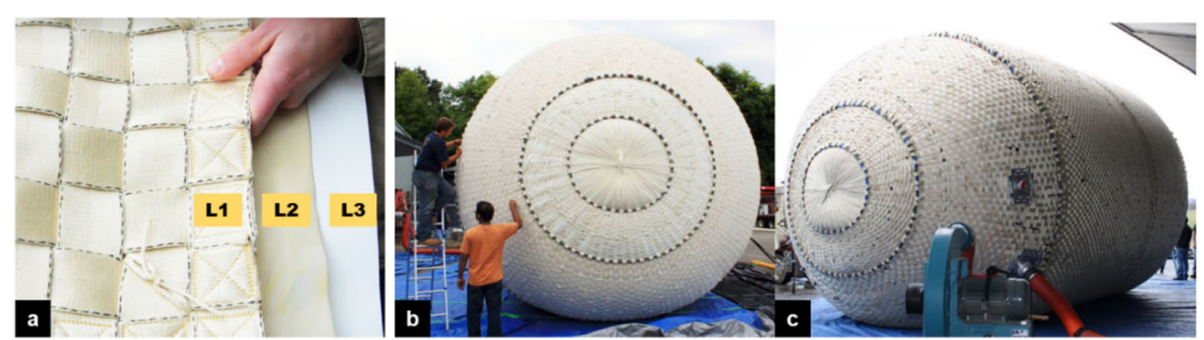

Fig. 6 Phase 2b. a Three-layer membrane configuration comprised of Vectran woven webbing (L1), protective Vectran fabric layer (L2), and inner bladder layer of urethane-coated polyester (L3). Unconfined inflation of (b) full-scale three-layer surrogate plug; (c) full-scale three-layer Vectran plug $[44,87,88]$

deployed, inflated, pressurized and finally subjected to flooding pressures while remaining stable. Overall, there were 24 full-scale tests conducted during Phase $2 \mathrm{~b}$. Of those, 11 tests involved the surrogate plug with air (Fig. 8), and 13 tests used the Vectran plug pressurized to $7 \mathrm{kPa}$. The three final tests using the Vectran plug continued with full water pressurization and tunnel flooding simulation with an average internal plug pressure of $119 \mathrm{kPa}$ (17.3 psig), and an average flooding pressure of $80 \mathrm{kPa}$ (11.7 psig), respectively, as described in [44, 88].

Quarter-scale testing provided an initial range of coefficient of friction of the Vectran webbing against a cylindrical concrete surface. Test results were in the range of $\mu=0.19$ to 0.4 in a flooded environment. Slippage testing showed that when the ratio between the external, or flooding pressure $\left(\mathrm{P}_{\mathrm{e}}\right)$, and the internal, or plug pressure $\left(\mathrm{P}_{\mathrm{i}}\right)$, ranged from 0.95 to 1.0 , it resulted in the axial movement of the plug [88]. In this set of tests, the internal water pressure ranged from 69 to $469 \mathrm{kPa}(\sim 10$ to $\sim 68$ psig), and the external flooding pressure ranged from 34 to $345 \mathrm{kPa}(\sim 5$ to $\sim 50 \mathrm{psig})$. These results established the basis for further development of the technology and for its successful transitioning to end-user organizations. Phase $2 \mathrm{~b}$ also provided valuable experience in plug design, construction, handling, deployment, and inflation, setting the stage for improved plug reliability. In particular, folding and packing of the plug were determined to be key parameters in ensuring success and repeatability of plug deployment and conformity to tunnel geometry, and work on this area during Phase 2b set the stage for successful progression of techniques in the subsequent Extended Testing Phase and Phase 3. An overview of the key features of the inflatable plug, objectives, and results from Phase $2 \mathrm{~b}$ is summarized in Table 2.

\section{Phase 2b: multi-layer membrane design, extended testing} (ET)

Additional testing was carried out during the Phase $2 \mathrm{~b}$ Extended Testing Phase to achieve the following objectives:

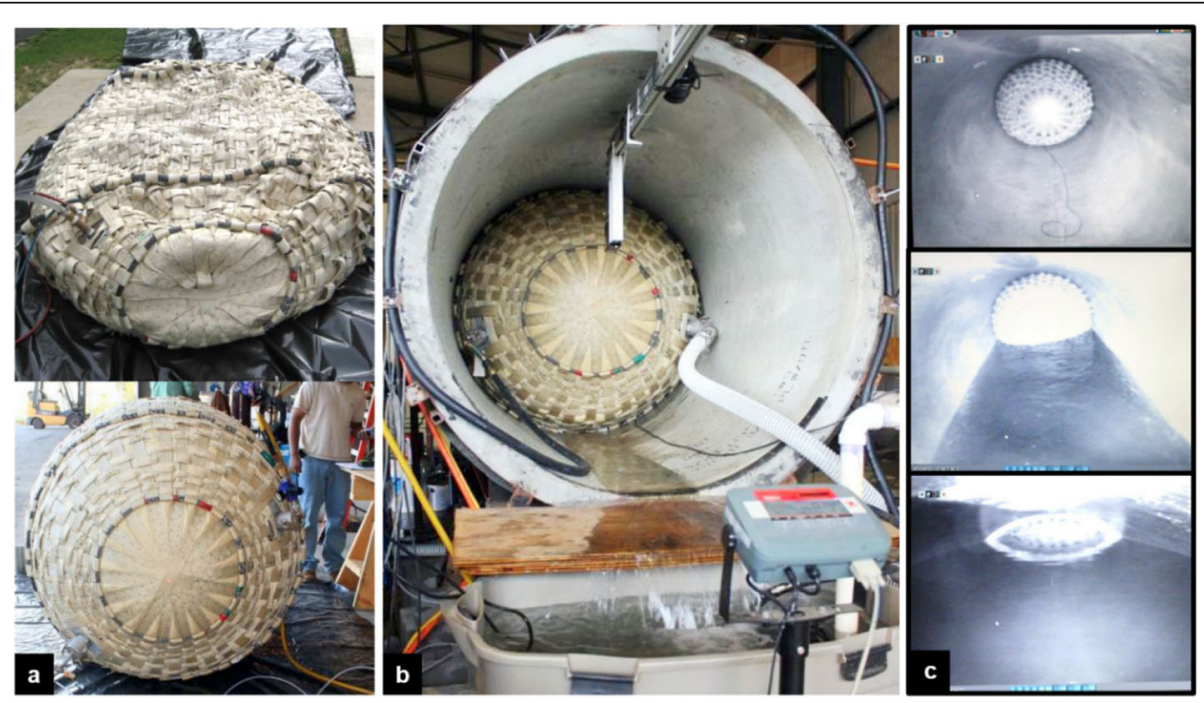

Fig. 7 Phase 2b, reduced-scale testing: a Unconfined inflation of quarter-scale plug; b Front view of confined inflation and flooding simulation; c Back view quarter-scale tunnel during flooding testing [89] 


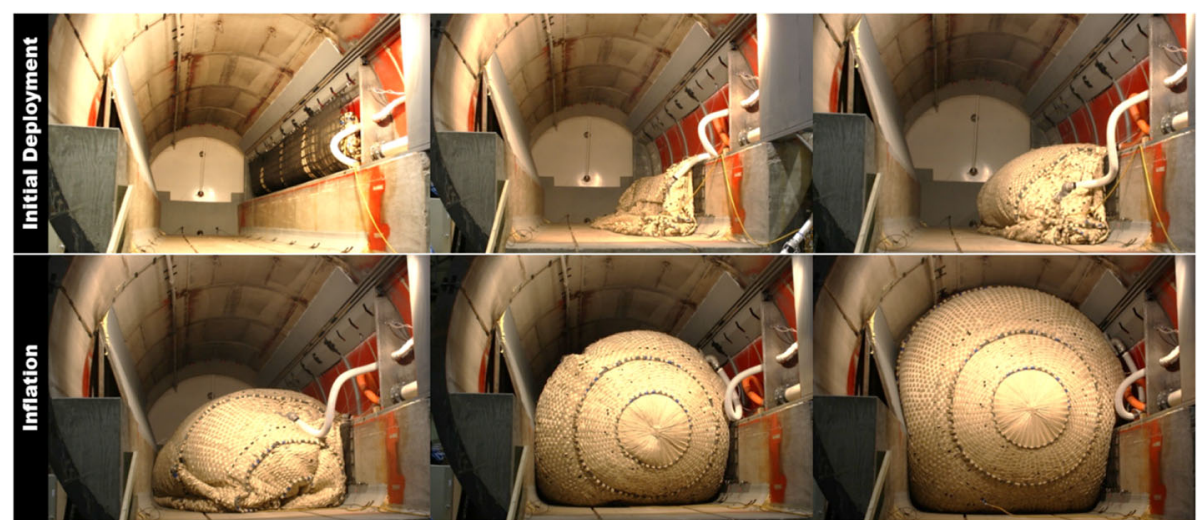

Fig. 8 Phase 2b, full-scale testing, and three-layer Vectran plug. Deployment and low-pressure air inflation for the initial positioning of the plug before flooding simulation $[44,88]$

- Integrate the Phase 2b multi-layer plug with the modular, soft-pack container for improved installation characteristics in working tunnels, and assess the performance of the soft-pack container.

- Demonstrate repeatability of successful plug deployment and plug conformity to provide an adequate tunnel seal.

- Establish a range of acceptable leakage rates measured during full-scale flooding simulations.

- Evaluate the impact of changes in plug oversizing ratio.

With these objectives in mind, activities focused on the following areas:

a) Modifications to the Full-Scale Tunnel Mockup: The full-scale tunnel mockup configuration was modified to simplify the integration of the plug and removable container module, which required the development of new handling procedures for packing the plug into the container and mounting the module in the tunnel mockup. The tunnel contours were also tailored (e.g., by easing corners) to provide for improved conformability of the plug to the tunnel contact perimeter and thus provide a more effective seal against the tunnel walls. This had previously been identified as an area that could help reduce floodwater leakage rates in the prior phase.

b) Development of Handling Procedures for Integrated Plug/Soft-Pack Container Module: Folding and general handling procedures needed to be developed for packing the plug in the soft-pack container and then mounting the loaded container into the tunnel mockup for testing. This method of installing the plug in the tunnel is more representative of handling procedures that could be used in actual transit tunnels than the previous permanently installed hard container. An overview of the folding and packing sequence developed during this phase is illustrated in Fig. 9.

c) Full-Scale Plug Testing: The Extended Testing Phase was conducted at WVU, with occasional support from the plug manufacturer to check the performance of the manufacturing details of the plug and the softcover container. Numerous deployments with both the surrogate and the Vectran full-scale plugs allowed the development of indicators to systematically quantify the level of global and local plug conformity and contact achieved during each test. Additional full-scale flooding simulations at design pressures allowed measurement of leakage pressures and contact pressures as well as estimations of water leakage rates.

d) Quarter-Scale Plug Testing: Additional quarterscale testing was conducted in the quarter-scale tunnel during the Extended Testing Phase to evaluate the effect of the degree of plug oversizing on the performance of the plugging system. Testing was conducted first at the original $1.22 \mathrm{~m}$ (48-in.) diameter of the test apparatus, and then at a reduced test apparatus diameter ( $1.17 \mathrm{~m}$ or $46 \mathrm{in}$.). The reduction in test apparatus diameter increased the percentage of plug oversizing from 2\% to $6.1 \%$. The Extended Testing Phase provided additional knowledge for further development and refinement of systematic methods to evaluate plug deployments that were subsequently used during Phase 3 . The general steps for each of the full-scale tests included: 1) Folding and packing of the plug in the container as shown in the sequence of Fig. 9; 2) Mounting of the container in the tunnel mockup; 3) Plug deployment and initial air inflation at low pressure and an 


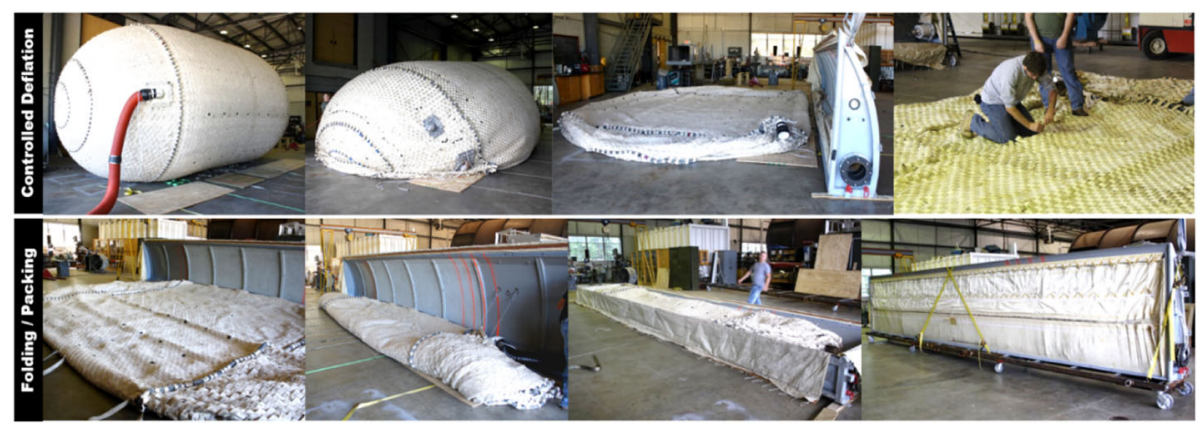

Fig. 9 Phase 2b-ET, full-scale testing, and three-layer Vectran plug. A sequence of controlled deflation, folding and packing into the soft-cover container $[44,69,88]$

airflow of $42 \mathrm{~m}^{3} / \mathrm{min}\left(1500 \mathrm{ft}^{3} / \mathrm{min}\right)$ as illustrated in Fig. 10; 4) Completing a conformity check to determine and record how well the plug conformed to the tunnel geometry for that test as shown in Fig. 11; and 5) Full plug pressurization with water followed by water flooding testing (only with the Vectran Plug).

After a set of preliminary deployments for adjusting operational and testing procedures using the soft-pack container, a total of 27 full-scale tests were conducted during the Extended Testing Phase. Of those, 19 involved the use of the surrogate plug with low-pressure air $(7 \mathrm{kPa})$ and eight used the Vectran plug with lowpressure air $(7 \mathrm{kPa})$ first, and then two continued with water pressurization up to $120 \mathrm{kPa}$ and flooding simulation at a pressure of $80 \mathrm{kPa}$ as illustrated in Fig. 12 and
Fig. 13. For each one of these tests, two complementary methods were used to measure the conformity of the plug to the tunnel contours: A) a visual scoring/rating system, and B) sensor strips installed on the floor, ceiling, and walls of the tunnel to measure plug contact (see Fig. 11). A key feature to significantly increase the conformity of the plug to the tunnel was the attachment of passive restraining devices (i.e., break cords) during the folding process (see Fig. 9). These passive restraining devices contributed to ensuring the sequential release of fabric material through the deployment process leading to improved and more reliable levels of local and global conformity of the plug to the tunnel section. A detailed description of testing procedures and results for conformity evaluations is presented in $[69,88]$.

The Extended Testing Phase also provided significant information on the effects of different degrees of plug
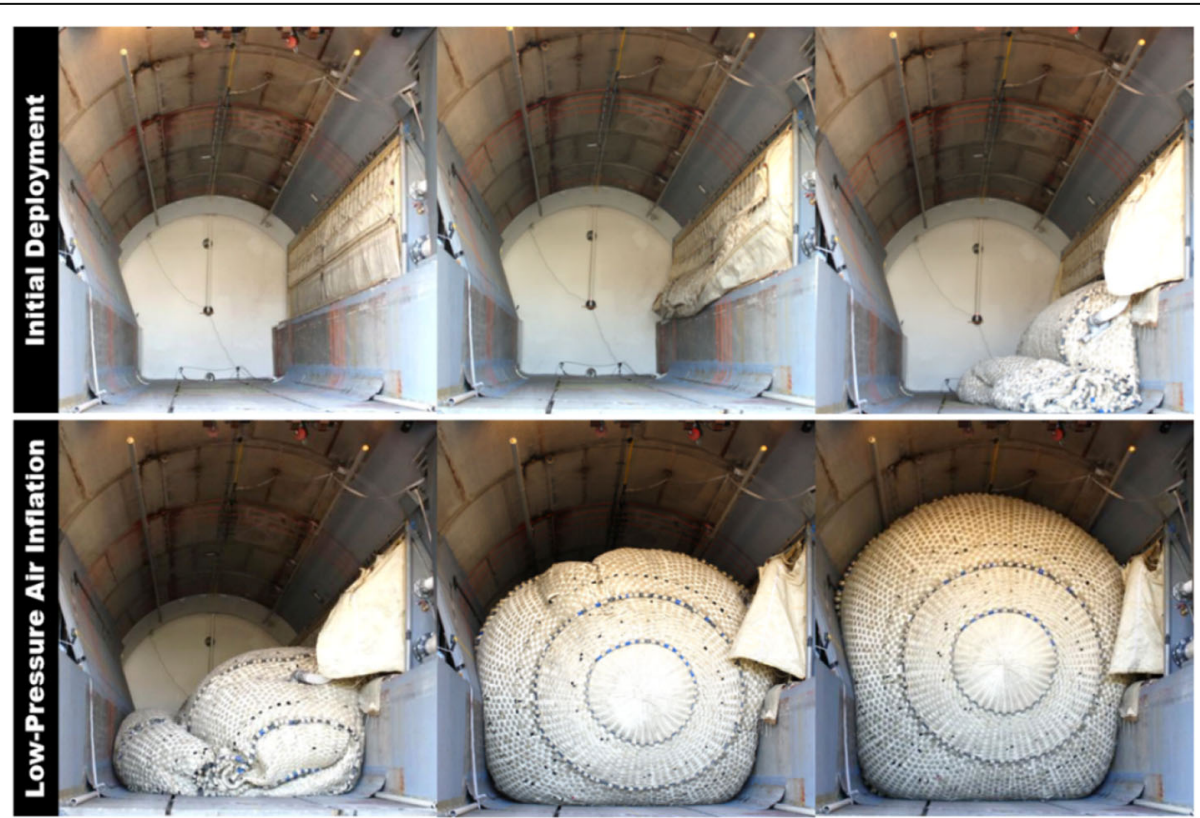

Fig. 10 Phase 2b-ET, full-scale testing, and three-layer Vectran plug. A sequence of initial deployment from softcover container followed by lowpressure air inflation before flooding simulation $[69,88]$ 


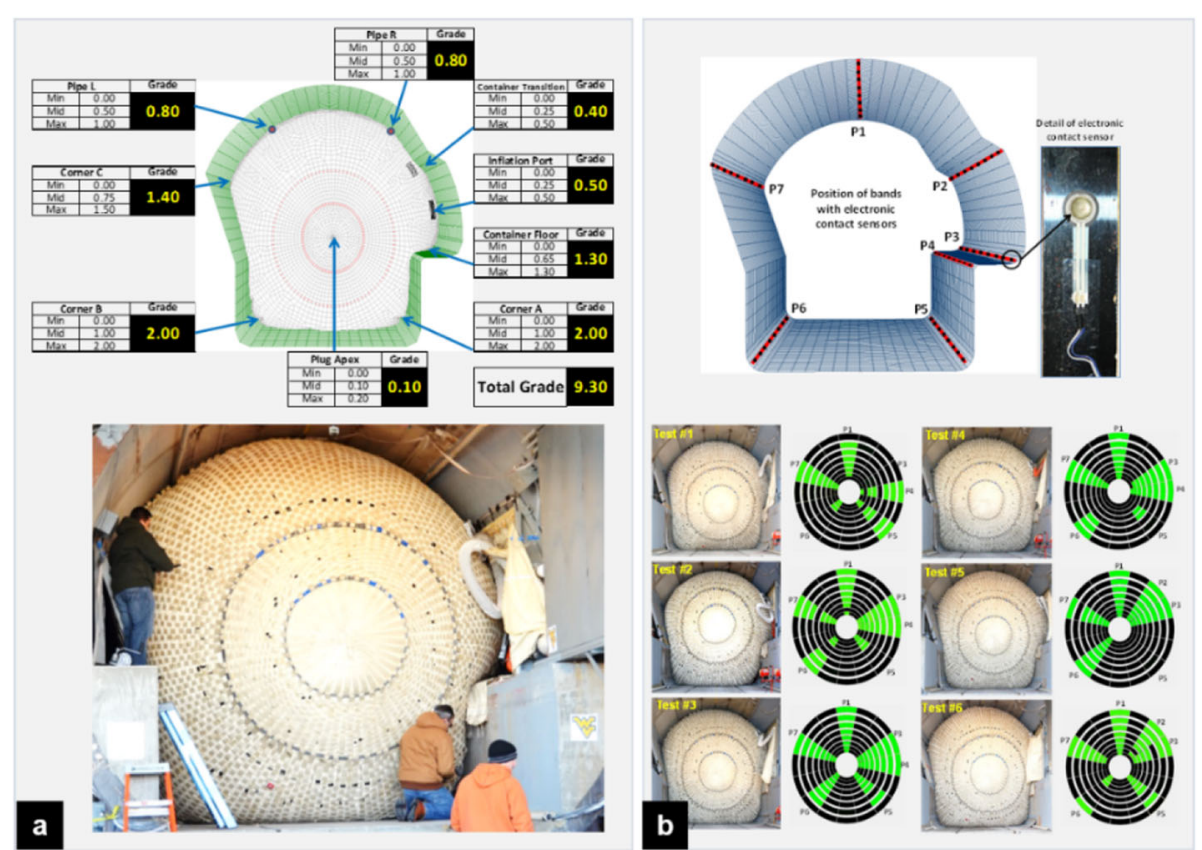

Fig. 11 Phase 2b-ET, full-scale testing, three-layer Vectran plug: a Evaluation matrix (top) and inspection after initial deployment and inflation; b Location of strips with contact sensors in the tunnel (top) and contact maps for different tests after initial inflation at $7 \mathrm{kPa}[69,88]$

oversizing on plug performance, which fed into the design of the prototype plug subsequently developed and tested during Phase 3. The quarter-scale tests demonstrated that increased oversizing improved the level of contact along the perimeter of the cylindrical portion of the plug. However, the optimum level of oversizing is a tradeoff because the increased oversizing led to increased longitudinal wrinkles that could serve as a pathway for leakage past the plug. Moreover, with the number of deployments and subsequent handling of the different plugs, post-test plug examination also gave insights into the durability of the plug and the methods used to fabricate the plug, helping to ensure a reasonable service life for future application in a working tunnel and to refine some plug design and manufacturing details to improve plug performance. The results of the visual inspection indicated several locations of significant abrasion of the outer woven Vectran layer and signs of wear and tear caused by handling on the rough concrete surfaces in the tunnel mockup after 30 deployments. Overall, the Extended Testing Phase resulted in a sound basis for a decision to proceed with a prototype system

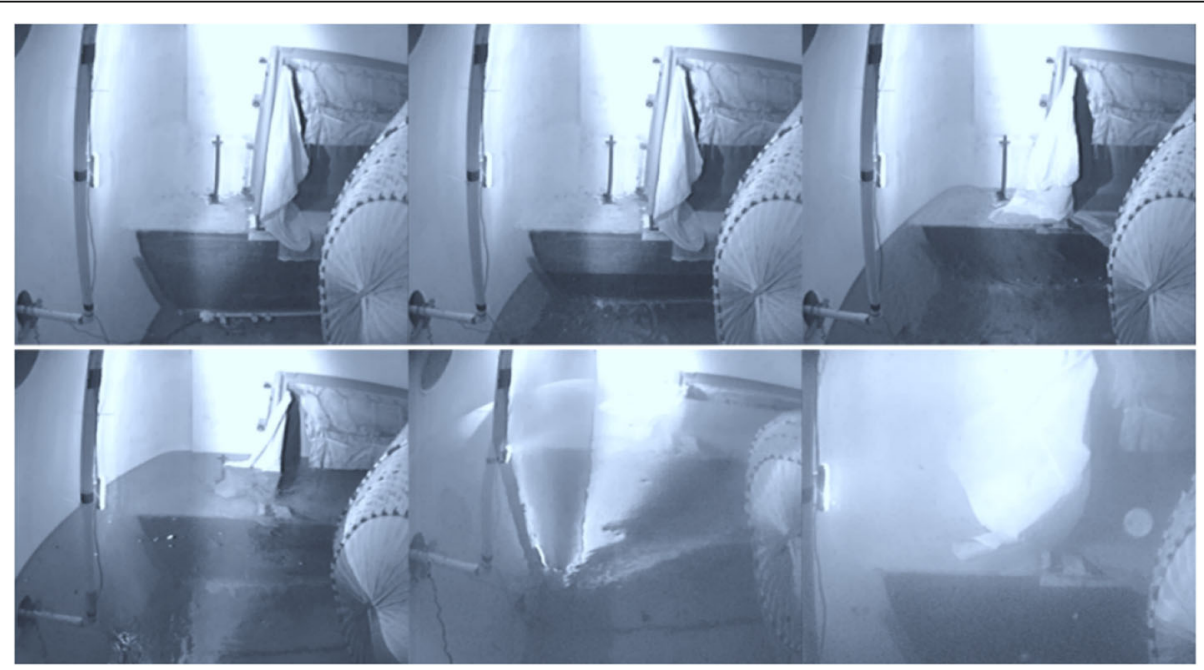

Fig. 12 Phase 2b-ET, full-scale testing, three-layer Vectran plug: Back view during filling of tunnel cavity for flooding simulation [69, 88] 


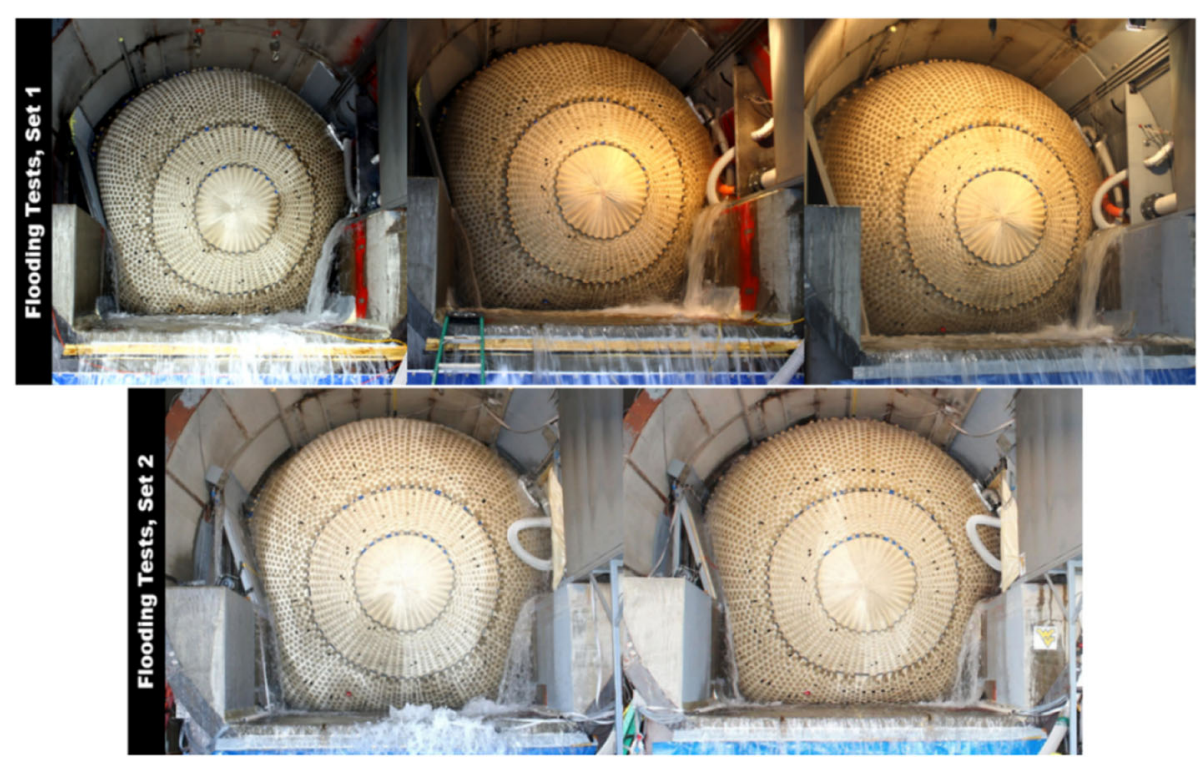

Fig. 13 Phase $2 b$-ET, full-scale testing, three-layer Vectran plug: Front view of flooding tests carried out for Phase $2 b$ (top row) and Phase $2 b$-ET (bottom row) $[69,88]$

design and testing that followed during Phase 3. A summary of the testing objectives and results obtained from Phase $2 \mathrm{~b}$ Extended Testing is presented in Table 2.

Phase 3 - prototype system testing and long-term testing Phase 3 was focused on developing and testing a complete prototype plug system to verify readiness for installation in working transit tunnel systems. The prototype system that was tested during Phase 3 was based on a design for a complete integrated system in response to end-user interest. Phase 3 was conducted to verify total system readiness for installation in working tunnels. This required relocation and reconfiguration of the existing tunnel mockup as well as fabrication of other components for the tunnel plug system, including the inflation system and the inflation control system. Testing activities carried out as part of Phase 3 were focused on the following three main areas:

a) Material Testing: Additional material testing was conducted early in Phase 3 to account for changes introduced with the Phase 3 design including: 1) Friction testing of the Vectran webbing on the updated concrete surface and the new coating material introduced in the tunnel mockup to cover simulated metal surfaces; 2) Flammability testing of the new coating material applied to some of the tunnel surfaces to increase friction resistance; 3 ) Tensile testing of the new design break cords introduced in Phase 3 to ensure predictable and repeatable performance during plug deployment. b) Relocation and Reconfiguration of Tunnel Mockup: To allow pressurization with air, the tunnel mockup was relocated to the manufacturer's facility. In addition to the relocation, the interior of the tunnel was reconfigured to represent the geometry for future use in appropriate sections of end-user tunnels as well as to facilitate moving the plug and container module and other equipment in and out of the tunnel.

c) Full-scale Testing: Although the prototype design tested in Phase 3 was based mainly on the plug design used in Phase $2 \mathrm{~b}$ and on the softcover container design tested during the Extended Testing Phase, there were enough differences in the design that some technical challenges needed to be revisited. These technical challenges included reliable release and deployment of the plug from the container, selection of reliable and robust components for the inflation system connection to the plug, and assurance of plug conformity to the tunnel geometry. Phase 3 was the first phase of the project employing full plug pressurization with air, rather than low-pressure air deployment followed by final full pressurization with water as used during Phase $2 \mathrm{~b}$ and the Extended Testing Phase. Figure 14 shows a sequence of initial deployment and air inflation before the flooding simulation.

A total of 49 tests were completed during Phase 3. Tests 1 to 17 focused on obtaining a reliable soft cover container opening Tests 18 to 40 concentrated on obtaining a reliable and repeatable. Tests 41 to 48 focused on short- 
duration full-scale flooding simulations with the plug pressurized with air to $120 \mathrm{kPa}$ and flooding water at 80 $\mathrm{kPa}$ and served to verify the consistency of procedures as well as to measure the leakage rates. Figure 15 illustrates a sequence of images captured during one of the short duration flooding simulations. Finally, Test 49 consisted of a long duration performance evaluation in which the inflatable plug was subject to 21 days of full operating average pressure of $120 \mathrm{kPa}$ combined with total flooding average pressure of $80 \mathrm{kPa}$, while remaining in a stable position with relatively constant leakage rate. Test 49 was also used to verify the air inflation and pressurization system integrity, plug integrity, plug positioning over a long-term operation campaign.

During the set of tests outlined above, the RTP system was demonstrated to perform as designed and meet the key requirements relating to the plug inflation time, floodwater containment (as defined by leakage rate around the plug), and resistance to movement from floodwater pressures. The system was also successfully demonstrated to operate for 21 days [91, 92], following a requirement to provide time until appropriate longerterm measures can be taken to control the flooding. A summary of the testing objectives and results obtained from Phase 3 is presented in Table 2.

\section{Discussion of main lessons learned}

During the execution and evaluation of the experimental work corresponding to each of the phases described previously, several lessons were learned along the way. The following is a compilation of the main lessons learned.

\section{Phase 1 - proof of concept}

- Regarding the geometric shape of the inflatable, a plug comprised of a cylindrical segment and two spherical caps is one of the most straightforward structural configurations that can be designed and manufactured. In this phase, a fitted cylindrical shape was adopted in the small and large scale prototypes to ensure conformity of the plug to the tunnel perimeter (see Fig. 2 and details of the inflatable plug reported in [42]). On the other hand, the limit on the size and maximum inflation pressure is controlled by the strength of the fabric that constitutes the membrane of the inflatable. In Phase 1, the inflatable prototype was manufactured only for proof of concept at a relatively low inflation pressure (less than $7 \mathrm{kPa}$ or 1 psig). For this reason, a readily available commercial fabric (polyester with flexible PVC coating) was selected as material for manufacturing the initial prototypes recognizing that a much stronger fabric material would be needed for higher inflation pressures required to contain flooding pressures. Similar membrane materials were used in the smallscale prototypes tested in $[33,35,36]$ in their lowpressure $(<1.5 \mathrm{kPa})$ evaluations.

- Careful preparation of the plug, including folding, packing and installation of passive restrainers during the folding process, was essential to achieving a compact folded shape first, and then, to produce a sequential release of the membrane to control the unstressed fabric material better as it gradually deployed and accommodated to the form of the tunnel profile. Tests conducted during Phase 1 at reduced scale showed that if the plug does not conform well to the tunnel perimeter during the initial stages of the deployment, the friction and weight of the plug will counteract the expanding effect of the pressure and gaps will remain open despite an increase of inflation pressure. In this regard, similar results were observed in the study carried out by Kim et al. (2018) [36] who used a small-scale prototype and showed that the sealing effectiveness increases with the inflation pressure until the inflatable cannot expand anymore and it locks into the tunnel with the shape achieved at the initial lower pressure.

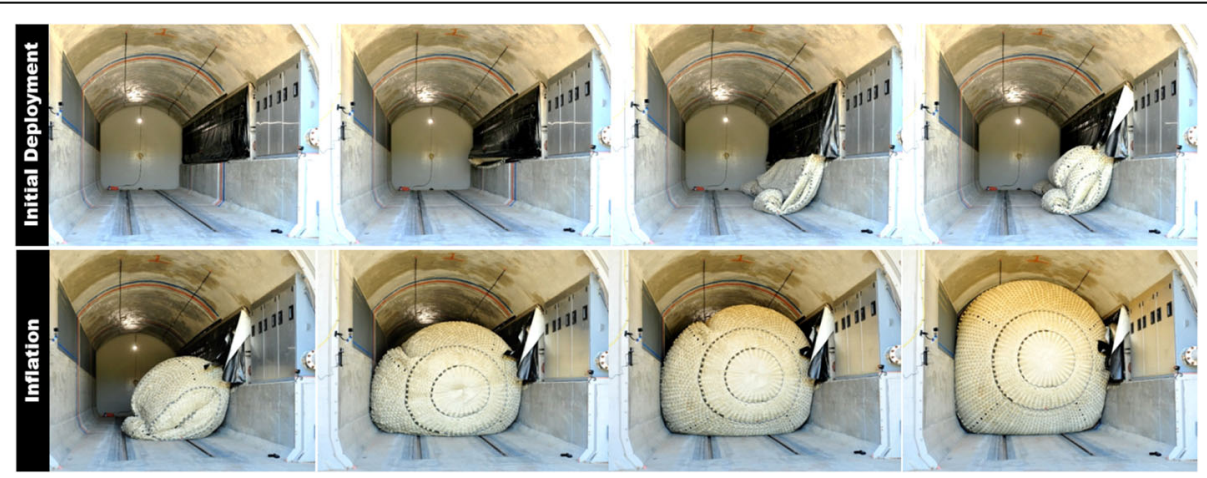

Fig. 14 Phase 3, full-scale testing, three-layer Vectran plug. A sequence of initial deployment from softcover container followed by pressurization with air inflation before flooding simulation [91, 92] 


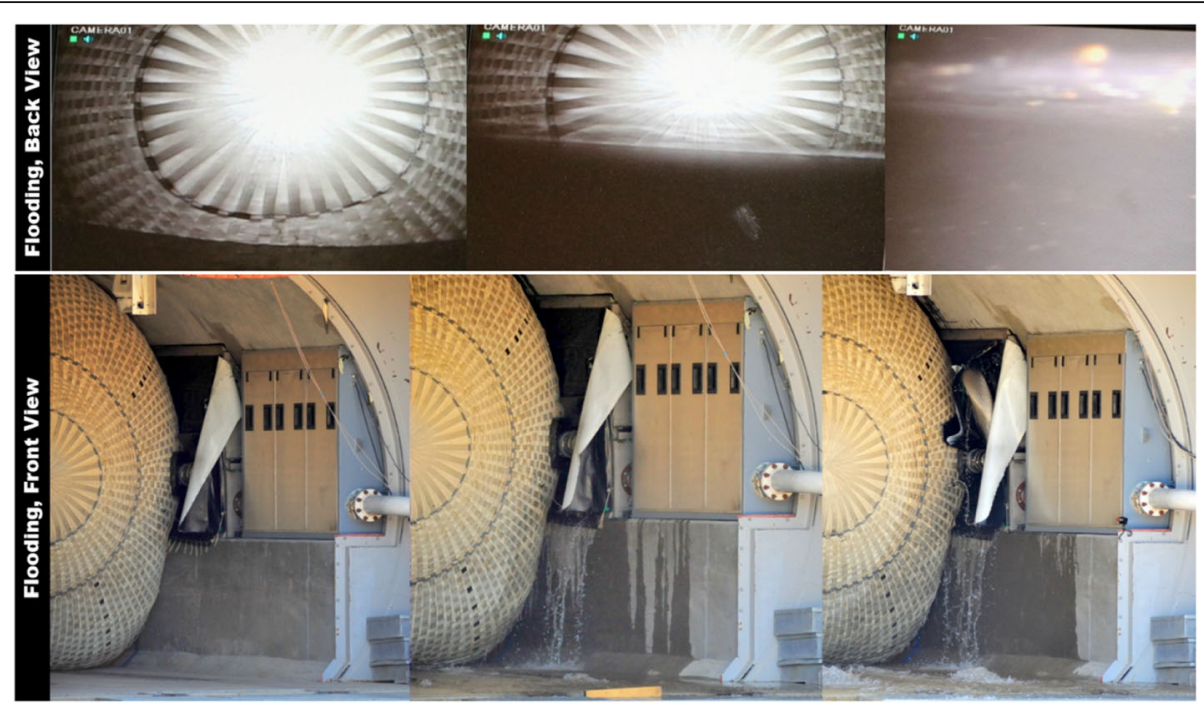

Fig. 15 Phase 3, full-scale testing, three-layer Vectran plug. Back view of the tunnel cavity during water filling for flooding simulation (top) and corresponding front view during flooding simulation (bottom) [91, 92]

- Tests in an actual tunnel section demonstrated that the folded inflatable plug could be successfully installed, deployed and inflated within a specified period. The pilot test conducted in a service tunnel [42] showed that a lightweight compactly packed inflatable could be installed in less than twenty-four hours, without interfering with the rail car's dynamic envelope. The prototype used in this test was successfully deployed by gravity, filled with about $110 \mathrm{~m}^{3}$ of air and then pressurized in less than $5 \mathrm{~min}$ up to a pressure of $7 \mathrm{kPa}$. The closest successful attempt to seal an actual tunnel cross-section was performed in the tests with inflatable of annular shape in the Netherlands [30].

- Full-scale tests conducted in Phase 1 also demonstrated that major utility lines and piping along tunnel walls and ceiling could create pathways for leakage and such lines and piping would have to be repositioned or otherwise be covered to minimize these leakage pathways. A smoke test conducted during the full-scale test of [42] showed the flow of smoke created along pipes and cables in contact with the plug. These results confirmed the need to include an oversizing (in the range of 10 to $15 \%$ ) in the transversal perimeter of inflatable to have extra membrane material that could close the gaps generated by the presence of pipes, cables and duct banks. Similar observations were made in the smallscale experiment carried out by Yoo et al. (2016) [35].

\section{Phase 2 - single layer membrane design}

- During this phase, two types of Vectran fabric were used to manufacture quarter and full-scale prototypes. Initially, a single-side coated Vectran fabric was used to build and test a quarter-scale prototype. Then a double-side coated Vectran fabric was used to manufacture and test a second quarter-scale and a full-scale prototype. Both fabrics had a nominal tensile strength of $403 \mathrm{kN} / \mathrm{m}$ ( 2300 pounds/inch). As a reference, the PVC coated polyester used during Phase 1 had a nominal tensile strength of about $80 \mathrm{kN} / \mathrm{m}$ ( 460 pounds/inch). However, both types of Vectran fabrics demonstrated to be sensitive to abrasion produced by continuous handling, folding and routine operations required for testing. This sensitivity resulted in the failure of the first quarterscale plug manufactured with the single-coated Vectran fabric during the long term evaluation at pressures in the range of 345 to $468 \mathrm{kPa}$. A new quarterscale was built with the double-coated Vectran fabric that, when subjected to minimal handling, passed successfully the long-term evaluation and additional tests of sealing capacity and slippage. This same double-coated Vectran fabric was used to manufacture a full-scale plug, which survived three partial flooding simulations tests before failure. Abrasion appeared to be again the possible cause of failure. Further abrasion tests at coupon level showed a reduction of tensile strength for a relatively high number of cycles (75\% reduction of strength after 500 cycles of abrasion at a $7 \mathrm{kPa}$ normal pressure) 
associated to handling. However, the actual prototypes at the quarter and full scales appeared to be more sensitive, and this eventually reduced the nominal tensile strength of the Vectran fabrics implemented during this phase.

- In terms of design and manufacturing of the plug, although a fitted shape of the cylindrical portion of the plug looked promising in Phase 1, it demonstrated to be more challenging to manufacture and to handle as the Vectran fabric became stiffer due to the increased strength required for higher levels of pressurization and the addition of a double-sided, thicker coating to protect the fibers from abrasion and to withstand the frictional forces.

- Moreover, the additional stiffness of the Vectran fabric altered the folding pattern, increased the packed volume about two times, and ultimately created stress concentrations that led to the failure of the fabric material during pressurization. It was ultimately determined that the single-layer of Vectran fabric could not be relied upon to provide sufficient strength to meet the reference pressure $(124 \mathrm{kPa})$.

- An important lesson learned from this phase was that the position of the folded plug in the tunnel section determines the dynamics of the initial deployment and subsequent sealing effectiveness. In Phase 1, the initial deployment and positioning of the plug within the tunnel during the inflation took advantage of the ceiling deployment in which gravity drove the initial expansion of the inflatable and then was enhanced by the sequential release of the membrane as described in [42]. Ceiling deployment was also attempted in the reduced-scale tests performed in [36] with variable degrees of sealing effectiveness depending on the final level of pressurization and the time of application of the pressure. In Phase 2, the folded plug was positioned on a lateral duct bank, as shown in Fig. 4. In this position, the action of gravity is limited to only the initial unrolling of the plug from the container, and it requires the activation of the inflation system to drive the membrane up. Incorporating passive restrainers along the cylindrical section of the plug ensures that the plug membrane is positioned around the perimeter of the tunnel.

\section{Phase $2 \mathrm{~b}$ - multiple layer membrane design, initial testing}

- The adoption of a three-layer fabric system for the membrane increased the plug's strength and resilience. Unlike the single-layer design, in the threelayer, the loads originated at the different stages of the preparation and pressurization of the plug were carried by the different fabric layers of the membrane. In the quarter-scale tests $(1.22 \mathrm{~m}$ tunnel diameter) completed during this phase, the inflatable plug was taken safely to the reference pressure of $468 \mathrm{kPa}$ while holding a flooding pressure of $330 \mathrm{kPa}$ without slipping $[88,89]$. As a reference, the reduced-scale studies carried out in $[32,35,36]$ included tunnel diameters in the range of $0.2 \mathrm{~m}$ to 0.4 $\mathrm{m}$ for pressures in the range of $10 \mathrm{kPa}$ to $50 \mathrm{kPa}$.

- The decoupling of the functions of the plug membrane prevented compromising unloaded segments of fabric material during pressurization. It also reduced localized abrasion occurring during folding and installation procedures. In this regard, it was determined that a design that provided a minimum factor of safety (strength of materials divided by calculated strength requirement) of four (4) for soft-goods strength in the hoop direction would provide adequate assurance of being able to meet the strength need. Additionally, it was determined by analysis that a safety factor of around three (3) would be sufficient at the interface between the metallic hardware fittings and the soft-good materials.

- The implementation of a three-layer fabric system for the membrane added significant weight to the inflatable. The transition from a single-layer design to a multi-layer design increased the weight by a factor of about 10. That is, from about $150 \mathrm{~kg}$ for the single-layer full-scale Vectran fabric plug to about $1600 \mathrm{~kg}$ corresponding to the full-scale three-layer plug. This significant increase in mass required developing new handling procedures for folding and installation in the tunnel, including auxiliary membranes to transport and place the folded plug inside the hard-cover container and to keep it in place once installed as illustrated in Figs. 8 and 9.

- In terms of the geometrical design of the inflatable plug, the fitted shape adopted during Phases 1 and 2 was replaced by a straight cylindrical segment that simplified part of the manufacturing process. In this regard, the studies conducted in [32-36] have also adopted this simple geometric configuration in their studies at different scales. The plug's cylindrical segment required an amount of oversizing, defined as the ratio of the plug circumference to the effective circumference of the tunnel, at the point where the plug is to be used. Experiments demonstrated that some degree of oversizing is prudent to ensure that there is sufficient membrane to extend into all transition areas and to account for any misalignments in the deployment. Tests with the full-scale surrogate plug with oversizing in the range of $2 \%$ to $10 \%$ demonstrated that being on 
lower end ( $\sim 2 \%$ which is close to the manufacturing tolerance) does not leave room for misalignments during the initial deployment and increases the chances of creating bridging of membrane material at transitions in the tunnel perimeter. However, too much oversizing (around 10\%) can lead to uneven membrane material distribution which favors the formation of large longitudinal wrinkles or distorted shapes that can cause uneven stresses on the plug with localized stress concentrations and can provide possible pathways for increased leakage rates.

- The quarter and full scales flooding simulations carried out in the 1.2-m and 4.8-m tunnel diameters, respectively, demonstrated that maintaining the inflatable plug at a pressure 1.5 times the flooding pressure ensured the axial stability of the plug at the location of deployment as described in detail in $[43,44,89]$. This margin of safety is similar to the values achieved in reduced scale test reported in [34] in their simulations for an inflatable plug deployed and pressurized in a 5.9-m diameter tunnel.

- The installation of passive restrainers (or break cords) during folding helped to control the release of the membrane, particularly in the upper regions of the tunnel perimeter. Changes in the weight of the plug membrane between phases due to material changes required the identification of new break cord materials and higher-capacity passive restraints able to hold the additional weight and to break at the appropriate time $[69,88]$. The concept of controlling the deployment of the membrane was adopted from aerospace applications where different types of inflatables are used for various functions [93-97]. The maximum tensile force of a single break cord needed for the Phase 1 prototype was in the range of 130 to $150 \mathrm{~N}$. The three-layer plug required break cords in the range of 750 to $850 \mathrm{~N}$ to maintain the membrane held during the initial deployment as shown in Fig. 16. Figure 16 (top) also illustrates the experimental sequence of holding of the membrane by the passive restrainers during inflation until the plug reaches the upper region of the tunnel and then the release of the stored membrane material upon breakage of the restrainers located in the top left-hand crease in the plug. Based on these results, the installation of passive restrainers was also implemented systematically during the full-scale tests carried out during Phases $2 \mathrm{~b}-\mathrm{ET}$ and 3.

- Experimental results of Phase $2 \mathrm{~b}$ demonstrated the importance of implementing an adequate folding technique to guide the initial deployment of a heavy membrane. In order to reduce the experimental iterations, finite element simulations were carried out to explore different folding patterns and inflation sequences for the full-scale plugs [45-47]. Simulations helped to try folding patterns such as zig-zag or rolling, as well as to implement inflator models, such as the Uniform Pressure Method, which are similar to those applied in the simulations of automobile airbags [98-102], and large-scale inflatables for other civil engineering applications [103-105]. Simulations also helped to identify the position of the membrane fold held by the passive restrainers created to "save" membrane material necessary to cover the upper regions of the tunnel perimeter as illustrated in Fig. 16 (bottom), where a cross-section of the plug shows how the break cords held the membrane until the inflation pressure reached a threshold value of $180 \mathrm{~Pa}$ to $220 \mathrm{~Pa}$ before reaching full confinement.

\section{Phase $2 \mathrm{~b}$ - multiple layer membrane design, extended testing}

Extended testing with the implementation of a softcover portable container enabled the systematization of the testing procedures developed in the previous phases for a full-scale prototype. Extended testing showed that the implementation of inflatable plugs for sealing tunnel segments can be divided into three main stages:

- Stage I: Preparation and installation of the inflatable. It requires the definition and implementation of a folding sequence in conjunction with the packing of the folded plug into the portable storage container. The position of the container in the tunnel depends on the type of tunnel as well as the type and condition of the primary tunnel liner system, as described in Section 1.3(e). This phase also includes the transportation and installation of the folded plug at specific locations inside the tunnel segment to be sealed, leaving it ready to be deployed when needed.

- Stage II: Deployment. It begins with the automatic opening of the storage container, which allows the liberation of the inflatable (as shown in Fig. 10) and followed by inflation until it reaches its final shape and position within the tunnel section. The deployment and initial inflation of the plug are performed using air at relatively high flow rates, typically in the range of 25 to $50 \mathrm{~m}^{3} / \mathrm{min}$ (900 to $1800 \mathrm{ft}^{3} / \mathrm{min}$ ), to allow a relatively rapid expansion and positioning of the inflatable within a time range of 2 to $5 \mathrm{~min}$. With these airflow rate levels, the internal pressure of the plug is relatively low, less than $7 \mathrm{kPa}$, which allowed close inspection and evaluation of the quality of the local conformity during testing. 


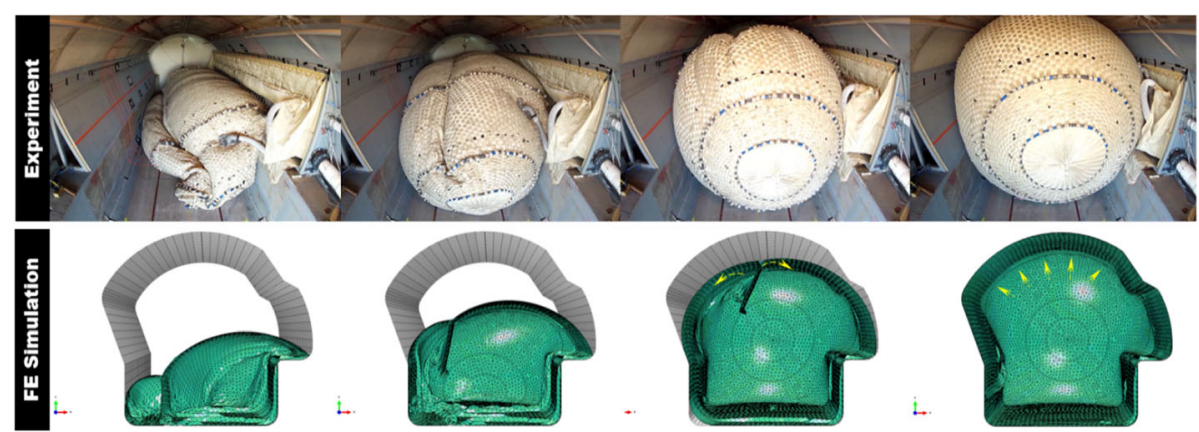

Fig. 16 Phase 2b-ET, full-scale testing, and three-layer Vectran plug. Initial inflation and holding of membrane material by passive restrainers (top). For additional details see [[69]92-94]. Cross-section of finite element simulation of initial inflation and sequence membrane release upon breakage of passive restrainers [45-47]

- Stage III: Pressurization. It begins immediately after the initial positioning. In this stage, the plug is pressurized up to the reference pressure, so it can withstand, predominantly by friction, the external pressure originated by flooding. The magnitude of the pressurization depends on the level of flooding pressure expected to be contained [43, 44, 69, 88]. The reference parameters used in the tests carried out during this phase included a target deployment and a pressurization time of $20 \mathrm{~min}$. In this time, the plug was fully deployed, positioned in the 4.9-m diameter tunnel mockup, and pressurized with internal pressure at $120 \mathrm{kPa}$, to withstand a flooding pressure of $80 \mathrm{kPa}$ while remaining axially stable and operational for 2 hours during the monitoring of the leakage rate. These values are lower than the values used in the simulation studies carried out by Liao et al. (2017) [34] where an internal pressure of 220 $\mathrm{kPa}$ and an average flooding pressure of $83 \mathrm{kPa}$ were assumed for the stability analyses of an inflatable plug installed in a 5.9-m diameter tunnel.

- Extended testing also demonstrated that the sealing capacity of the pressurized inflatable is highly influenced by the level of local and global conformity achieved during Stage II, which in turn depends on how the inflatable was prepared in Stage I, i.e., plug folding and packing procedures demonstrated to be critical to proper plug deployment. A relatively compact folding along with the attachment of break cords during the folding contributed to: first, achieving correct alignment during the initial unrolling, and second, ensuring a sequential release of fabric material held by the passive restrainers during the initial inflation, leading to improved levels of global and local conformity, respectively.

- By employing systematic plug folding and packing procedures, plug deployments were made more reliable, which helped to ensure sufficient conformity and sealing to provide an effective mechanism against floodwaters, reducing leakage to an acceptable rate. Leakage rates decreased as the levels of global and local conformity increased, as illustrated in Fig. 17, which compares the results of the visual inspection scores with the leakage rates obtained during Phase $2 \mathrm{~b}$ and Phase 2b-ET. Subsequent analysis demonstrated that the visual scoring/ rating system for plug conformity to the tunnel contours was at least as reliable as and less complicated than using contact sensor strips. This scoring system was based on visual inspection of key locations in the contact perimeter and assigning scores ranging from 1 (the lowest score indicative of no local contact of the membrane with the tunnel perimeter) and 10 (the highest score indicative of full contact of the plug membrane, particularly in corners and transitions). As shown in Fig. 17, an increase in the level of conformity led to an increase of about 2 points in the score (7.1 to 9.3), which in turn reduced in about half the leakage rate $\left(2.8 \mathrm{~m}^{3} / \mathrm{min}\right.$ to $1.5 \mathrm{~m}^{3}$ / min), which is indicative of an overall better sealing quality of the plug. As also shown in Fig. 17, flooding simulations allowed a better estimation of the range of leakage rates that would need to be managed by drain pumps normally installed in the tunnels. Average leakage rates measured during Phase 2b Initial and Extended Testing ranged from $1.5 \mathrm{~m}^{3} /$ $\mathrm{min}(393 \mathrm{gal} / \mathrm{min})$ to $2.8 \mathrm{~m}^{3} / \mathrm{min}(729 \mathrm{gal} / \mathrm{min})$ with an average of $2.1 \mathrm{~m}^{3} / \mathrm{min}(552 \mathrm{gal} / \mathrm{min})$. These values established a baseline that was used for reference for the flooding simulations carried out during Phase 3.

- Extended testing also provided insights into the durability of the plug and the methods used to fabricate the plug. During Phase $2 b$ Initial and Extended Testing, more than 20 full-scale tests were 


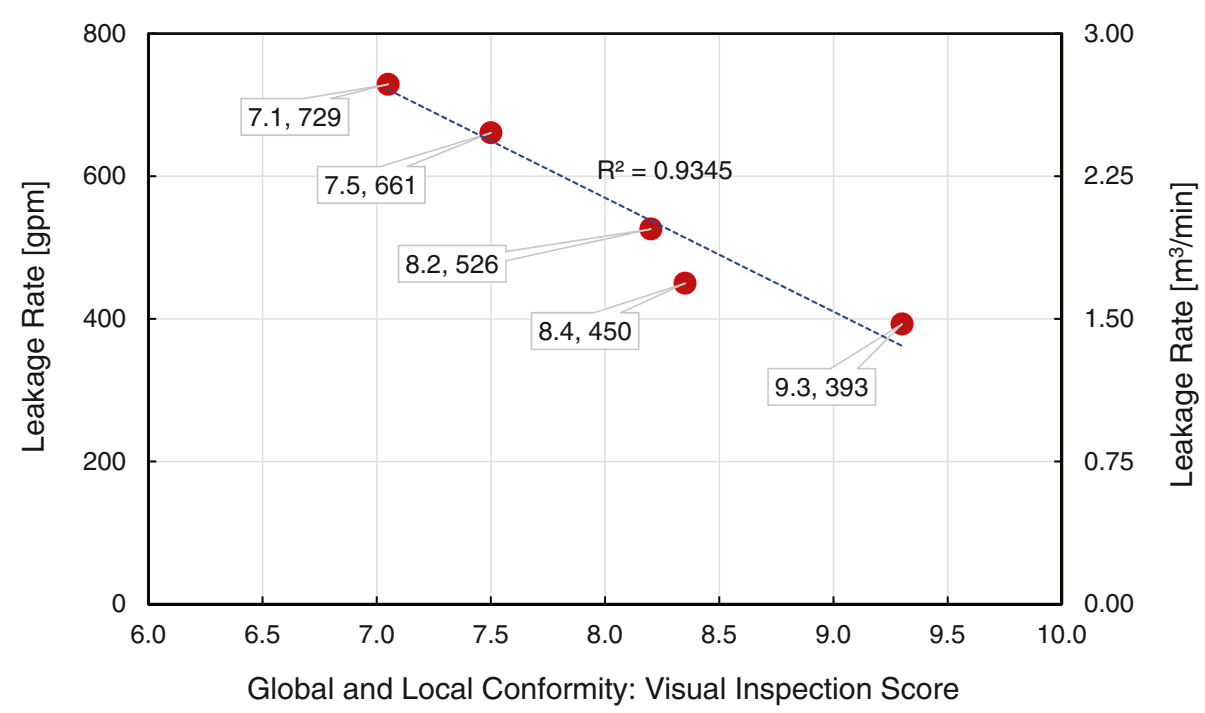

Fig. 17 Leakage rates vs. Inspection scores obtained from flooding simulations completed during Phase $2 b$ and Phase $2 b-E T$. Scale range for scoring system $\min =0$ and $\max =10[69,88]$

completed using the three-layer Vectran plug, including sixteen (16) low-pressure dry deployments and five (5) full-pressure flooding simulations that were carried out to adjust folding procedures, installation sequence and leakage measurements. Post-test examination of the plug showed signs of abrasion of the outer layer of woven webbings, and also signs of wear and tear in the inner layers caused by general handling, folding, deployment, pressurization and removal manoeuvres carried out during the multiple tests.

- It is anticipated that during the implementation in a tunnel system, the production plug installed in the tunnel would be tested before installation and during scheduled maintenance periods, typically for a year. Based on the testing to date, it is anticipated that the plug could be deployed at least 20 times for testing and maintenance purposes without significant degradation in its performance and membrane strength. However, if an actual flooding event occurred, it is anticipated that the plug would not be re-used due to debris or containments from the flooded area, possibly damaging the plug. Further long-term evaluations will be needed in the future to quantify the long-term performance.

\section{Phase 3 - prototype system testing and demonstration}

Phase $2 \mathrm{~b}$ Initial and Extended Testing provided valuable experience on several aspects of the design and testing of the full-scale inflatable plug, handling of portable soft-cover container, and calibration of the inflation system. Based on this experience, revisions were made in the design and operation of the container cover, the cover release mechanism, the inflation hose, and plug folding and packing procedures to provide more reliable and robust service of the RTP system during the tests completed during Phase 3, including:

- One of the main differences between the tests completed during Phase $2 \mathrm{~b}$ and Phase 3 was the way in which the full-scale three-layer Vectran plug was pressurized. In Phases $2 \mathrm{~b}$ and $2 \mathrm{~b}-\mathrm{ET}$, the plug was initially deployed by a combination of gravity and activation of the inflation system at a low-pressure $(7 \mathrm{kPa})$ and also at a relatively high air flow rate $(42$ $\mathrm{m}^{3} / \mathrm{min}$ or $\sim 1500 \mathrm{ft}^{3} / \mathrm{min}$ ), which was useful to position the plug in the tunnel. The final pressurization was then achieved with water pumped into the plug until the testing plug pressure of $120 \mathrm{kPa}$ was achieved. In Phase 3, the initial positioning was also achieved with high-flow and low-pressure air, but the final pressurization was completed with compressed air supplied by the inflation system installed on the side of the tunnel mockup. No significant performance differences were observed in sealing effectiveness using water or air as the fluid to pressurize the plug, other than the additional time required to pressurize the plug (about 20 to $30 \mathrm{~min}$ with water vs 10 to $15 \mathrm{~min}$ with compressed air).

- As in the previous testing phases, reliable release and initial deployment of the plug from the container was essential to the operational reliability of the RTP system. Portions of the sequence of packing of the plug into the container were simplified over the testing and the use of inflation air optimized to ensure the proper, consistent 
deployment behavior. More than 30 low-pressure air deployment trials were needed to bring all of these different factors together to work out a reliable plug packing, release, and deployment. Consistent deployment and inflation of the plug to achieve conformity with the modified tunnel geometry also required fine-tuning of plug packing procedures, including the use of break cords to control the placement of the plug material to ensure filling the tunnel without leaving open pathways for water leakage around the plug.

- One of the issues that emerged during Phase 3 prototype system testing was inflation hose durability. This is the hose that acts as a flexible duct between the plug and the inflation system piping, and requires rotational and translational degrees of freedom during deployment and initial inflation. The Phase 2 systems incorporated two 0.1$\mathrm{m}$ diameter hoses that conveyed the necessary airflow to deploy the plug and then the required water flow to pressurize the plug. Conversely, in Phase 3, a single 0.3-m diameter composite flexible hose was initially selected for full air deployment and pressurization. However, despite the flexibility, the larger hose was found to lack the necessary strength and durability to stand up to repeated packing and deployment cycles. Maintaining the single-hose design, a 0.3-m diameter hose with metal braiding provided the needed resiliency and durability, but with less flexibility than similar diameter multilayer composite or Kevlar/silicone hoses. According to reduced-scale experimentation reported in the literature [32-36, 89] the interaction between the inflatable plug and the means that convey the pressurization fluid to the plug was trivial and did not constitute a matter of significant concern. However, in full-scale experimentation and field implementation, problems can occur as the size and stiffness of the inflation hose can affect the deployment, which in turn could affect the final positioning, and ultimately diminish the sealing capacity and leakage containment ability of the plug.

- With all of the system components tuned to perform reliably, full-scale tests completed during Phase 3 demonstrated and validated the repeatability of performance at two levels: (a) Multiple shortduration ( 1 to $3 \mathrm{~h}$ ) flooding simulations in which the plug remained stable and with the leakage rates below $2.6 \mathrm{~m}^{3} / \mathrm{min}$ (700 gal/min); (b) A single longduration test during which the plug maintained an internal pressure of $120 \mathrm{kPa}$ while withstanding a flooding pressure of $80 \mathrm{kPa}$ and remaining axially stable during 21 consecutive days in which the leakage rate also remained constant at below $2.6 \mathrm{~m}^{3} / \mathrm{min}$
(700 gal/min). These two levels of testing demonstrated and validated the long-duration system performance in which all performance requirements were met. Ultimately, the testing results of Phase 3 provided extensive operational experience with the latest generation plug and container system with full-pressure air inflation that can be used for the final transition and installation in the field [91, 92].

Finally, Table 3 summarizes the number of tests conducted during the different phases of the RTP Project organized by testing category, including material testing, reduced-scale testing, and full-scale testing. As summarized in Table 3, more than 400 tests were conducted on fabric specimens and webbing specimens to determine tensile strength and frictional properties at the coupon level. Over 200 tests were conducted with reduced-scale prototypes, of which 185 were used to reproduce flooding conditions and full plug pressurization before conducting full-scale tests. During the different phases, a total of over 100 full-scale tests served to verify different aspects of the membrane and plug design, manufacturing, folding, packing, installation, deployment and control of the membrane material, sealing capacity and stability of the different experimental prototypes. The culmination of the full-scale testing was the 12 successful flooding simulations using the three-layer membrane design during which tests the inflatable tunnel plug was effectively deployed remotely and withstood flood pressure while remaining stable.

\section{Conclusions}

An overview of different technical aspects, design considerations, developmental phases and main test results corresponding to the RTP Project are summarized in this paper. The RTP project was a ten-year design, development, testing, and demonstration project of a portable system to install in tunnel systems to restrain flooded water from entering other sections of the tunnel system. The project developed over three major phases.

Test results obtained in Phase 1 demonstrated the viability of installing and deploying a low pressure, fullscale inflatable plug in an actual tunnel segment within the time and space constraints imposed by the operations of a typical railway tunnel. Test results from Phase 1 demonstrated that a single layer membrane formed by a cylindrical segment and two hemispherical endcaps could be inflated in 3 to $5 \mathrm{~min}$ and could contain smoke reasonably well. Phase 1 results also showed the need for modifications on the tunnel profile to improve the local conformity and more effective sealing.

Test results obtained in Phase 2 demonstrated the limitations of a high strength single layer design in its ability to withstand the pressurization of the plug in tests at full 
Table 3 Summary of the number of tests per phase and scale of testing

\begin{tabular}{|c|c|c|c|c|c|c|c|}
\hline \multicolumn{2}{|l|}{ Membrane Design } & \multicolumn{2}{|c|}{ Single Layer } & \multicolumn{3}{|c|}{ Three Layer } & \multirow[t]{2}{*}{ Totals } \\
\hline Testing Category & & Phase 1 & Phase 2 & Phase $2 b$ & Phase $2 \mathrm{~b}-\mathrm{ET}$ & Phase 3 & \\
\hline \multirow[t]{4}{*}{ Material Testing } & Tensile testing & 32 & 90 & 9 & 9 & 21 & 426 \\
\hline & Friction Testing & 60 & 120 & 60 & & 15 & \\
\hline & Shear Testing & & 3 & 5 & & & \\
\hline & Flammability Testing & & 1 & & & 1 & \\
\hline \multirow[t]{3}{*}{ Reduced-Scale Testing } & Low-pressure air inflations (1:5.7) & 6 & & & & & 202 \\
\hline & Low-pressure air inflations (1:4) & & 5 & 3 & 3 & & \\
\hline & Full Pressure/Flooding Simulation (1:4) & & 50 & 35 & 100 & & \\
\hline \multirow[t]{3}{*}{ Full-Scale Testing } & Low pressure air inflations ${ }^{b}$ & $10^{\mathrm{a}}$ & 12 & 11 & 19 & & 109 \\
\hline & Low pressure air inflations ${ }^{c}$ & $1^{\mathrm{a}}$ & 3 & 10 & 6 & 22 & \\
\hline & Full Pressure/Flooding Simulation ${ }^{c}$ & & $3^{d}$ & 3 & 2 & 7 & \\
\hline
\end{tabular}

Notes: ${ }^{\text {a }}$ Preparation tests in the lab plus demonstration test in the tail tunnel with the same prototype; ${ }^{b}$ Surrogate plug; ${ }^{\mathrm{c}}$ Final testing prototype; ${ }^{\mathrm{d}}$ Plug pressurization only, no tunnel flooding. Results compiled from results reported in Molina (2008) [70]; Martinez et al. (2012) [42]; Barbero et al., (2013) [43, 44], Sill et al. (2013) [84]; Peil et al. (2014) [90]; Sosa et al. $(2014,2017)[69,88,89]$;

scale. These results prompted the development of a more robust membrane design carried out during Phase $2 \mathrm{~b}$.

Results obtained during Phase $2 \mathrm{~b}$ Initial and Extended Testing demonstrated the ability of a three-layer membrane design to withstand required inflation pressure, as well as flooding pressure while remaining stable. However, the adoption of a more robust membrane increased the weight and the handling difficulties and required the development of new folding, packing and installation procedures to obtain consistent and reliable performance in terms of initial deployment, global and local conformity, and sealing capacity. Moreover, experimental results obtained during Phase $2 \mathrm{~b}$ demonstrated that achieving acceptable local conformity at the beginning of the process of deployment and inflation with lowpressure air is critical for reducing the flood water leakage. Further improvements in the local conformity can be achieved by a combination of an adequate amount of oversizing the membrane material in contact with the tunnel perimeter, a controlled release of that material during the deployment with the implementation of passive restrainers, and modifications in the transitional zones of the tunnel perimeter in order to further reduce the leakage coming from those particular zones. Furthermore, flooding simulations produced non-negligible but controllable water leakage rates that can be managed with pumping equipment available in existing tunnel infrastructure.

Quarter-scale testing completed during Phase 2b served for verification of the friction at the system level and also to verify the strength of the three-layer construction before proceeding with the full-scale tests. Similarly, quarter-scale testing completed during Phase 2b-ET demonstrated that an increase in the oversizing of the plug increased the contact length between the plug and the test apparatus, which increased the holding resistance of the plug against the pressure of the floodwaters. However, the increase in the oversizing of the plug also seemed to increase the number and size of longitudinal wrinkles along the contact zone, which augmented the leakage rate around the plug. This information was useful to understand that although increased oversizing improved the level of contact along the perimeter of the cylindrical portion of the plug, the appropriate level of oversizing is a tradeoff because the increased oversizing led to increased longitudinal wrinkles that could serve as an additional pathway for leakage past the plug. Quarter-scale testing also served to test the behavior of the inflatable under induced slippage originated by depressurization of the plug. Results obtained in Phase 3 demonstrated the ability of a threelayer membrane design to be completely pressurized with air and to withstand flooding pressures without slipping. Test results obtained in Phase 3 also demonstrated the ability of the inflatable plug to remain stable for 21 days while subject to internal and flooding pressures and maintaining manageable leakage rates.

In closing, tests results obtained from the different testing scales completed during the different testing phases provided extensive design and operational experience. This allowed the development and evolution of the different components of the RTP system. The RTP system is now ready for transitioning and implementation as a tunnel flooding protection system.

\footnotetext{
Abbreviations

RTP: Resilient Tunnel Plug; WVU: West Virginia University; PNNL: Pacific Northwest National Laboratory; DHS: Department of Homeland Security; ET: Extended Testing; N: Newton.; Pa: Pascal; kPa: Kilo Pascal
}

\section{Acknowledgments}

This work was funded by the Science and Technology Directorate of the Department of Homeland Security (DHS). This paper was prepared as an 
account of work sponsored by an agency of the United States Government Neither the United States Government nor any agency thereof, makes any warranty, expressed or implied, or assumes any legal liability or responsibility for the accuracy, completeness, or usefulness of any information, apparatus, product, or process disclosed, or represents that its use would not infringe privately owned rights. Reference herein to any specific commercial product, process, or service by trade name, trademark, manufacturer, or otherwise does not necessarily constitute or imply its endorsement, recommendation, or favoring by the United States Government or any agency thereof. The views and opinions of authors expressed herein do not necessarily state or reflect those of the United States Government or any agency thereof.

\section{Authors' contributions}

E.M.S. performed the conceptualization, investigation, visualization, writing, and first draft preparation; G.J.T. contributed to the reviewing and editing of the manuscript; G.M.H. contributed to the writing, reviewing, editing and obtaining clearance for publication; J.M.F. contributed to the reviewing, editing, and obtaining clearance for publication. The authors read and approved the final manuscript.

\section{Author's information}

${ }^{1 *}$ Research Associate Professor, Project Coordinator, Co-Investigator, Principal Investigator, Department of Mechanical and Aerospace Engineering, West Virginia University, Morgantown, WV, USA ; Associate Professor, CoInvestigator, Department of Mechanical and Aerospace Engineering, West Virginia University, Morgantown, WV, USA 2 ; Project Manager, Emeritus Program, National Security Directorate, Pacific Northwest National Laboratory (PNNL), Richland, WA, USA ${ }^{3}$;Program Manager, Science \& Technology Directorate, Department of Homeland Security, Washington, DC, USA.

\section{Availability of data and materials}

Not applicable.

\section{Competing interests}

No competing or conflict of interest.

\section{Author details}

'Department of Mechanical and Aerospace Engineering, West Virginia University, Morgantown, WV, USA. ${ }^{2}$ Pacific Northwest National Laboratory, Richland, WA, USA. ${ }^{3}$ Department of Homeland Security, Science \& Technology Directorate, Washington, DC, USA.

Received: 9 July 2020 Accepted: 16 August 2020

Published online: 27 August 2020

\section{References}

1. Publication FHWA-IF-03-036 (2003) The blue ribbon panel report on bridge and tunnel security, recommendations for bridge and tunnel security, U.S. Department of Transportation

2. TCRP report 86/NCHRP report 525 (2006) Public transportation security, making transportation tunnels safe and secure, vol. 12. Transportation Research Board of the National Academies, Washington, D.C

3. Rabkin N (2007) Passenger rail security, federal strategy and enhanced coordination needed to prioritize and guide security efforts, U.S Government Accountability Office, Publication GAO-07-583T

4. Brezhnev VA, Abramson VM, Zemelman AM, Vlasov SN, Koulaguin NI, Merkin VE, Razbeguin VN (2005) Russian underwater tunnels in the system of international transportation ways. Tunn Undergr Space Technol 20:595599

5. Dammyr $\varnothing$, Nilsen $B$, Gollegger J (2017) Feasibility of tunnel boring through weakness zones in deep Norwegian subsea tunnels. Tunn Undergr Space Technol 69:133-146

6. Francesch-Huidobro M, Dabrowski M, Tai Y, Chan F, Stead D (2017) Governance challenges of flood-prone delta cities: integrating flood risk management and climate change in spatial planning. Prog Plan 114:1-27

7. Bridges O (2003) Double trouble: health risks of accidental sewage release. Chemosphere 52(9):1373-1379

8. Yin J, Yu D, Lin N, Wilby RL (2017) Evaluating the cascading impacts of sealevel rise and coastal flooding on emergency response spatial accessibility in lower Manhattan, new York City. J Hydrol 555:648-658
9. Inouye RR, Jacobazzi JD (1992) The great Chicago flood of 1992. Civil Engineering-ASCE 62(25):52-55

10. Post, Buckley, Schuh, Jernigan (2005) Hurricane Isabel assessment, a review of hurricane evacuation study products and other aspects of the National Hurricane Mitigation and preparedness program (NHMPP) in the context of the hurricane Isabel response National Oceanic Atmospheric Administration (NOAA).

11. New York City [NYC] Office of the Mayor (2013) PlaNYC: a stronger, more resilient New York, (2013) https://www1.nyc.gov/site/sirr/report/report.page. Accessed 1 July 2020

12. Zimmerman R (2014) Planning restoration of vital infrastructure services following hurricane Sandy: lessons learned for energy and transportation, 19. J Extreme Events 1(1):1-38

13. Plungis J, Keane A, Levin A (2012) Draining N.Y. tunnels flooded by Sandy to take many days http://www.bloomberg.com/news/2012-11-02/drainingn-y-tunnels-flooded-by-sandy-to-take-many-days.html. Accessed 1 July 2020

14. U.S. Army Corps of Engineers, Unwatering Team, (2012) http://www.mvr usace.army.mil/Portals/48/docs/CC/FactSheets/DewateringTeam-1Nov12.pdf. Accessed 1 July 2020

15. Leitner A (2001) The fire catastrophe in the Tauern tunnel: experience and conclusions for the Austrian guidelines. Tunn Undergr Space Technol 3(16): 217-223

16. Kirkland CJ (2002) The fire in the channel tunnel. Tunn Undergr Space Technol 17(2):129-132

17. Haack A (2002) Current safety issues in traffic tunnels. Tunn Undergr Space Technol 17(2):117-127

18. Morris R, Atkinson T (1987) The science and art of sealing a mine fire. Min Sci Technol 5:221-246

19. Conti RS (1994) Fire-fighting resources and fire preparedness for underground coal mines. U.S. Department of the Interior, USBM, IC 9410, Pittsburgh

20. Conti RS (2000) Mine rescue and response. In: Pr. Of the twelfth international conference on coal research, Sandton, South Africa, September 12-15, 2000, pp 127-136

21. Vervoort A, Declercq PY (2018) Upward surface movement above deep coal mines after closure and flooding of underground workings. Int J Min Sci Technol 1(28):53-59

22. Stocking A (2009) An inflatable tunnel seal stops flooding of world's largest undeveloped uranium mine https://bit.ly/2BZvkfa. Accessed 1 July 2020

23. Anwar HO (1967) Inflatable dams. J. of the hydraulics division. ASCE 93:99119

24. Watson R (1985) A note on the shapes of flexible dams. J Hydraul Res 23(2): 179-194

25. Carter C, Byun S, Marengo B (2001) Evaluation of inflatable dams for insystem storage utilization in CSO abatement. Urban drainage modeling. In: Brashear RW, Maksimovic C (eds) Proceedings of specialty symposium on urban drainage modeling at the world water and environmental resources congress, ASCE, Orlando, Florida, United States, may 20-24, 2001, pp 110 122

26. Ghavanloo E, Daneshmand F (2010) Analysis of the static interaction of fluid and cylindrical membrane structures. Eur J Mechanics A/Solids 29:600-610

27. Sklerov F, Padilla M (2012) DEP installs two inflatable dams in Brooklyn to help improve New York harbor water quality http://www.nyc.gov/html/dep/ html/press_releases/12-02pr.shtml. Accessed 1 July 2020

28. Gurt R, Deutscher M, Gebhardt M (2015) Design and analysis of reinforced rubber membranes for inflatable dams. In: Oñate E, Bletzinger KU, Kröplin B (eds) Proceedings of the VII international conference on textile composites and inflatable structures, structural membranes, Barcelona, October 19-21, 2015, pp 306-317

29. Tan GL (2002) Firefighting in tunnels. Tunn Undergr Space Technol 17:179-180

30. Lindstrand Technologies (2008) Successful inflatable tunnel plug tests in the Netherlands https://www.lindstrandtech.com/?p=587. Accessed 1 July 2020

31. Lyu HM, Shen SL, Zhou A, Yang J (2019) Perspectives for flood risk assessment and management for mega-city metro system. Tunn Undergr Space Technol 84:31-44

32. Chen J, Yan SW, Sun LQ, Lang RQ (2018) Theoretical analysis and model testing of the deformation characteristics and failure mechanism of a blocking airbag system in a tunnel under external pressure. In: Proceedings of GeoShanghai 2018 international conference: Tunnelling and underground construction, Shanghai, China, may 27-30, 2018, pp, pp 339-350 
33. Lu L, Qinliang Z, Yawei L, Qingqing Z, Gaohui L (2018) Fabrication of capsule-like inflatable woven fabric used for tunnel plugs. J Ind Text 48(5): 941-953

34. Liao A, Shang H, Kou X, Huang J, Zhuang X (2017) Modeling of 3D inflatable large deformation air plug in contact with concrete lining. In: Proceedings of the international conference on advances in computational mechanics, Acome 2017, Phu Quoc Island, Vietnam, august 2-4, 2017, pp 105-121

35. Yoo KS, Lee JH, Kim YD, Kim SH (2016) Friction behavior of inflatable structure system to protect rapidly flooding damages in subsea tunnel. J Kor Tunnelling Underground Space Assoc 18(1):109-117

36. Kim YD, Kong MT, Hwang BH, Kim SH (2018) An experimental study on the operation mode of rapid flooding protection system in tunnel. J Kor Tunnelling Underground Space Assoc 6(20):1147-1159

37. Ateknea Solutions Hungary Kft (2014) INFLATER - development of a universal flood protection tool using the force of the water to protect against floods https://cordis.europa.eu/project/rcn/100188/reporting/en. Accessed 1 July 2020

38. Oñate $E$, Flores FG, Marcipar I (2007) Membrane structures formed by low pressure tubes. New analysis methods and recent constructions International Center for Numerical Methods in Engineering (CIMNE), Publication CIMNE N 303, Spain

39. Rodríguez A, Oñate E, Marcipar J (2017) Design of an inflatable, modular and portable foot bridge International Center for Numerical Methods in Engineering (CIMNE), Publication CIMNE Nº 175, Spain

40. Optimal Umwelttechnik, Doppelkammerschlauch Flutschutz, (2019) https:// optimal-umwelttechnik.de/hochwasserschutz/doppelkammerschlauchflutschutz. Accessed 1 July 2020

41. Allen C, Averso M, Hargraves C, McNeil S (2015) Guide for the preservation of highway tunnel systems, NCHRP REPORT 816. The National Academies Press, Washington, D.C

42. Martinez X, Davalos J, Barbero EJ, Sosa EM, Huebsch W, Means K, Banta L, Thompson GJ (2012) Inflatable plug for threat mitigation in transportation tunnels. Proceedings of Society for the Advancement of material and process engineering (SAMPE) conference, Baltimore May 21-24, 2012

43. Barbero EJ, Sosa EM, Martinez X, Gutierrez JM (2013) Reliability design methodology for confined high-pressure inflatable structures. Eng Struct 51: $1-9$

44. Barbero EJ, Sosa EM, Thompson GJ (2013) Testing of full-scale confined inflatable for the protection of tunnels. Proceedings of the VI International Conference on Textile Composites and Inflatable Structures, Structural Membranes, Munich October 9-11, 2013

45. Sosa EM, Wong CS, Adumitroaie A, Barbero EJ, Thompson GJ (2016) Finite element simulation of deployment of large-scale confined inflatable structures. Thin-Walled Struct 104:152-167

46. Sosa EM, Wong CS, Barbero EJ (2016) Confined inflatable structures: from experiments to simulations. Proceedings of the XXII Congreso sobre Métodos Numéricos y sus Aplicaciones, ENIEF 2016, argentine association for computational mechanics (AMCA), CórdobaNovember 8-11, 2016, pp 313-330

47. Pecora I, Sosa EM, Thompson GJ, Barbero EJ (2019) FE simulation of ceiling deployment of a large-scale inflatable structure for tunnel sealing. ThinWalled Struct 140:272-293

48. Ricco P, Baron A, Molteni P (2007) Nature of pressure waves induced by a high-speed train travelling through a tunnel. J Wind Eng Industrial Aerodynamics 95:781-808

49. Rodler J, Hagenah B (2012) Determination of aerodynamic burden in rail tunnels using measurements and simulation. In: Proceedings of the 6th international conference on tunnel safety and ventilation, Graz, Austria, April 23-25, 2012, pp 124-131

50. Bickel JO, Kuesel TR, King EH (1996) Tunnel engineering handbook. Kluwer Academic Publishers, Massachusetts, pp 80-96 298-310

51. Hemphill GB (2013) Practical tunnel construction. Wiley, Hoboken, pp 381-389

52. Maidl B, Thewes M, Maidl U (2013) Handbook of tunnel engineering I: structures and methods. Wiley, Berlin, pp 45-59 124-136

53. O'Rourke TD (1984) Guidelines for Tunnel Lining Design, American Society of Civil Engineers, New York. https://webcache.googleusercontent.com/ search?q=cache:9ZNuFel4Yjc):https://cedb.asce.org/CEDBsearch/record.jsp\%3 Fdockey\%3D0041282+\&cd=1\&hl=en\&ct=clnk\&gl=us

54. American Underground Construction Association (2003) AUA guidelines for backfilling and contact grouting of tunnels and shafts. ASCE Press \& Thomas, Telford, pp 44-57
55. The British Tunnelling Society (BTS), the Institution of Civil Engineers (ICE) and Crown (2004) Tunnel lining design guide. Thomas Telford, London, pp 59-95

56. ITA Working Group No. 2 (2000) Guidelines for the design of shield tunnel lining. Tunnelling Underground Space Technol 15:303-331

57. Franzén T (1992) Shotcrete for underground support: a state-of-the-art report with focus on steel-fibre reinforcement. Tunn Undergr Space Technol 7(4):383-391

58. Zeidler K, Jager J (2007) Fiber reinforced shotcrete for tunnel linings. Proceedings of the first international conference on advances in concrete technology (RAC07), Fiber reinforced shotcrete for tunnel linings, Washington, D.C. September 19-20

59. Kenyon P (2015) Breaking new ground on LA outfall tunnel, Tunnel Talk http://www.tunneltalk.com/Los-Angeles-USA-02June2015-ClearwaterProgram-advances-design-of-critical-effluent-outfall-tunnel.php. Accessed 1 July 2020

60. ACl 544.7R (2016) Emerging technology report on design and construction of fiber-reinforced precast concrete tunnel segments. American concrete institute (ACI), Farmington Hills

61. Bakhshi M, Nasri V (2016) STR-998: design of fiber-reinforced tunnel segmental lining according to new ACl report. Proceedings of the Annual Conference of the Canadian Society for Civil Engineering: Resilient Infrastructure, LondonCanada, June 1-4, 2016, pp 1-10

62. ASCE (1989) Tunnels and shafts. Civil engineering guidelines for planning and designing hydroelectric developments. ASCE, Reston, pp 3-53-3-61

63. ASCE (2012) In: Bambei JH Jr (ed) Steel penstocks. ASCE manuals and reports on engineering practice no. 79. ASCE, Reston, pp 59-72

64. Brekke TL, Ripley BD (1987) Design guidelines for pressure tunnels and shafts. Electric Power Research Institute, final report AP-5273 EPRI, pp 5-17-5-32

65. Office of Energy Projects OEP (1997) Engineering guidelines for the evaluation of hydropower projects, chapter 10 - other dams. In: Federal Energy Regulatory Commission https://www.ferc.gov/sites/default/files/202 0-04/chap10.pdf. Accessed 1 July 2020

66. Gober H, Nackler K (2011) First operational experience with a high-pressure tunnel with innovative lining methods. Geomechanics Tunnelling 2(4):129-140

67. Grunicke UH, Ristic M (2012) Pre-stressed tunnel lining - pushing traditional concepts to new frontiers. Geomechanics Tunnelling 5(5):503-515

68. Gerstner R, Netzer E, Vigl A (2013) Long-term behaviour of pressure tunnels, Geomechanics Tunnelling 5(6):407-421

69. Sosa EM, Thompson GJ, Barbero EJ (2017) Experimental investigation of initial deployment of inflatable structures for sealing of rail tunnels. Tunn Undergr Space Technol 69:37-51

70. Molina JC (2008) Mechanical characterization of fabrics for inflatable structures MS Thesis, West Virginia University

71. Kuraray Co (2020) Vetran properties https://www.kuraray.us.com/products/ fibers/vectran, Accessed 1 July 2020

72. Cadogan D, Stein J, Grahne M (1999) Inflatable composite habitat structures for lunar and Mars exploration. Acta Astronaut 7-12(44):399-406

73. Cadogan D, Sandy C, Grahne M (2002) Development and evaluation of the Mars pathfinder inflatable airbag landing system. Acta Astronaut 50(10):633-640

74. Häuplik-Meusburger S, Sommer B, Aguzzi M (2009) Inflatable technologies: adaptability from dream to reality. Acta Astronaut 65(5-6):841-852

75. Hinkle J, Lin J, Kling D (2011) Design and materials study on secondary structures in deployable planetary and space habitats. Proceedings of the 52nd Structures, Structural Dynamics, and Materials Conference, AIAA 20112024, Denver April 4-7, 2011

76. Blamont J (2014) A roadmap to cave dwelling on the moon and Mars. Adv Space Res 54(10):2140-2149

77. Benaroya H (2017) Lunar habitats: a brief overview of issues and concepts. Reach (7-8):14-33. https://www.sciencedirect.com/science/article/abs/pii/ S2352309318300014

78. Tanaka M, Moritaka Y, Akahoshi Y, Nakamura R, Yamori A, Sasaki S (2001) Development of a lightweight space debris shield using high strength fibers. Int J Impact Eng 26(1-10):761-772

79. Akahoshi Y, Nakamura R, Tanaka M (2001) Development of bumper shield using low density materials. Int J Impact Eng 1-10(26):13-19

80. Tanaka M, Moritaka Y (2004) Single bumper shields based on Vectran fibers. Adv Space Res 5(34):1076-1079

81. Abtew MA, Boussu F, Bruniaux P, Loghin C, Cristian I (2019) Ballistic impact mechanisms - a review on textiles and fibre-reinforced composites impact responses. Compos Struct 223:110966 
82. Walters RJ, Garner JC, Lam SN, Vasquez JA, Braun WR, Ruth RE, Messenger SR, Lorentzen JR, Bruninga R, Jenkins PP, Flatico JM, Wilt DM, Piszczor MF, Greer LC, Krasowski MJ (2005) Materials on the international Space Station-forward technology solar cell experiment. Mater Sci Eng B 3(116): 257-263

83. Balagna C, Irfan M, Perero S, Miola M, Maina G, Crosera M, Santella D, Simone A, Ferraris M (2019) Antibacterial nanostructured composite coating on high-performance Vectran fabric for aerospace structures. Surf Coat Technol 373:47-55

84. Sill J, Means K, Sosa EM, Barbero EJ (2013) Friction and leakage characteristics of confined, reduced-scale inflatable structures. Proceedings of the VI International Conference on Textile Composites and Inflatable Structures, Structural Membranes 2013, Munich October 9-11, 2013

85. Kuraray Co (2012) Homeland security: a big plug for Vectran http://www. kuraray.us.com/kuraray-vectran-material-used-in-subway-plug. Accessed 1 July 2020

86. Hinkle J, Cadogan D, Roushey J, Cook R (2012) Design and testing of a resilient expandable structure using multi-layer softgoods technology. Proceedings of the 53rd structures, structural dynamics, and materials, AIAA 2012-1514, AIAA/ASME/ASCE, Honolulu April 23, 2012

87. Fountain $\mathrm{H}$ (2012) Holding back floodwaters with a balloon, The New York Times/Science Supplement http://www.nytimes.com/2012/11/20/science/ creating-a-balloonlike-plug-to-hold-back-floodwaters.html. Accessed 1 July 2020

88. Sosa EM, Thompson GJ, Barbero EJ (2014) Testing of full-scale inflatable plug for flood mitigation in tunnels. Transport Res Rec: J Transp Res Board 2407(2):59-67

89. Sosa EM, Thompson GJ, Barbero EJ, Ghosh S, Peil KL (2014) Friction characteristics of confined inflatable structures. Friction 2(4):365-390

90. Peil KL, Barbero EJ, Sosa EM (2012) Experimental evaluation of shear strength of woven webbings. Proceedings of the Society for the Advancement of material and process engineering (SAMPE) conference, Baltimore May 21-24, 2012

91. Peikes K (2017) ILC Dover shows off device to block flooding, terrorist threats in tunnel, Delaware Public Media, http://www.delawarepublic.org/ post/ilc-dover-shows-device-block-flooding-terrorist-threats-tunnels. Accessed 1 July 2020

92. Department of Homeland Security, Science and Technology (2017) Snapshot: a simple solution to protect critical infrastructure https://www. dhs.gov/science-and-technology/news/2017/06/21/snapshot-simplesolution-protect-critical-infrastructure. Accessed 1 July 2020

93. Salama M, Kuo CP, Lou M (2000) Simulation of deployment dynamics of inflatable structures. AIAA J 12(38):2277-2283

94. Katsumata N, Natori MC, Yamakawa H (2014) Analysis of dynamic behavior of inflatable booms in zigzag and modified zigzag folding patterns. Acta Astronaut 93:45-54

95. Schenk M, Viquerat AD, Seffen KA, Guest SD (2014) Review of inflatable booms for deployable space structures: packing and rigidization. J Spacecr Rocket 51(3):762-778

96. Wang JT, Johnson AR (2003) Deployment simulation methods for ultralightweight inflatable structures. NASA. In: Tm-2003-212410-ARL-TR-2973

97. Wang JT (2005) Dynamic deployment simulations of inflatable space structures. Proceedings of the 5th international conference on computation of Shell and spatial structures, Salzburg June 1-4, 2005

98. Wang JT, Nefske DJ (1988) A new CAL3D airbag inflation model. Proceedings of the international congress and exposition, SAE technical paper series 880654, Detroit February 29 - March 4, 1988

99. Wang JT (1995) An analytical model for an airbag with a hybrid inflator General Motors Research \& Development Center, Crashworthiness and Occupant Protection in Transportation Systems, ASME, AMD-210/BED-30

100. Ha WP, Park SJ, Spit HH (2004) Advanced curtain airbag modeling using the uniform pressure approach combined with a gas flow analysis SAE 01-1632

101. Lee JK, Ha WP, Lee JH, Chae DB, Kim JH (2009) Validation methodology on airbag deployment process of driver side airbag. Proceedings of the $21 \mathrm{st}$ enhanced safety of vehicles (ESV) conference, Stuttgart June 15-18, 2009, paper no. 09-0363

102. Potula SR, Solankia KN, Oglesby DL, Tschopp MA, Bhatia MA (2012) Investigating occupant safety through simulating the interaction between side curtain airbag deployment and an out-of-position occupant. Accid Anal Prev 49:392-403
103. Graczykowski C (2013) Theoretical models and numerical methods for adaptive inflatable structures. Proceedings of the Fourteenth International Conference on Civil, Structural and Environmental Engineering Computing, Stirlingshire 2013, Paper 0123456789

104. Li Q, Guo X, Qing Q, Gong J (2015) Dynamic deflation assessment of an air inflated membrane structure. Thin-Walled Struct 94:446-456

105. Li Q, Guo X, Gong J, Qing Q, Li Z (2016) Experimental deployment behavior of air-inflated fabric arches and a full-scale fabric arch frame. Thin-Walled Struct 103:90-104

\section{Publisher's Note}

Springer Nature remains neutral with regard to jurisdictional claims in published maps and institutional affiliations.

\section{Submit your manuscript to a SpringerOpen ${ }^{\circ}$ journal and benefit from:}

- Convenient online submission

- Rigorous peer review

- Open access: articles freely available online

High visibility within the field

- Retaining the copyright to your article

Submit your next manuscript at $\boldsymbol{\nabla}$ springeropen.com 